\title{
المفردات والتعبيرات الدالة على النميمة في نصوص التعاليم المصرية القديمة
}

دكتــور / إسلام إبر اهيم عامر محمد

المعهد العالى للسياحة والفنادق

كينج مريوط - الإسكندرية 


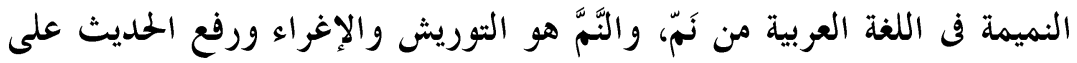

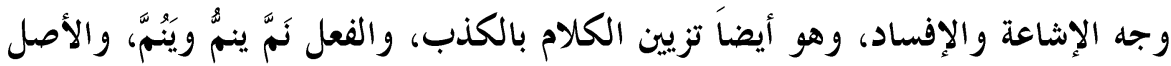

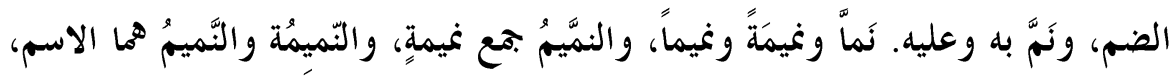

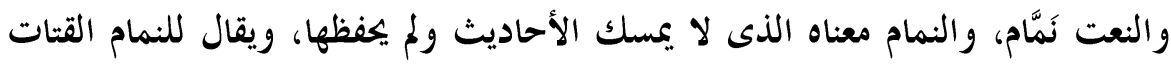

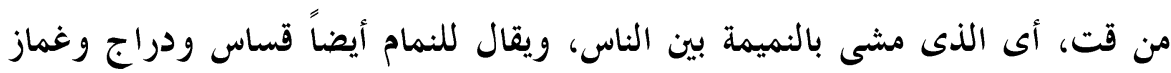

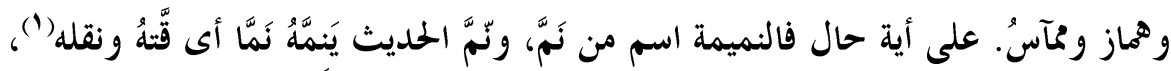

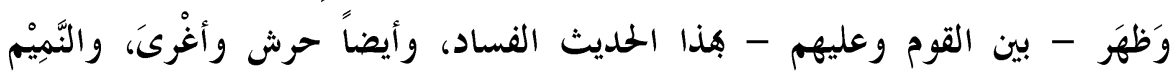

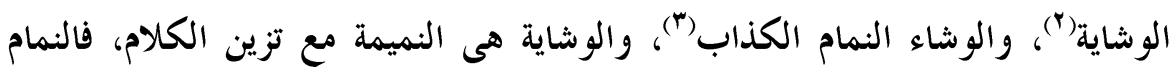

$$
\text { يَشي الكذب أى يولفه ويلونه ويزينه (\&). }
$$

واتفق علماء اللغة على أن النميمة هى نقل الحديث أو الكلام من قوم إلى قوم

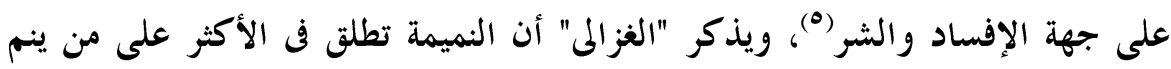

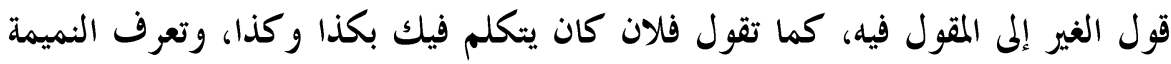
أيضاً بكشف ما يكره كشفه سواء كرهه المنقول عنه أو المنقول إليه أو كرهه طرف

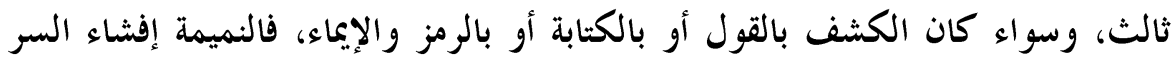
وكثف الستر عما يكره كثفه. والنميمة أصل العداوة المريقة للدماء(") ويقول الله تعالى

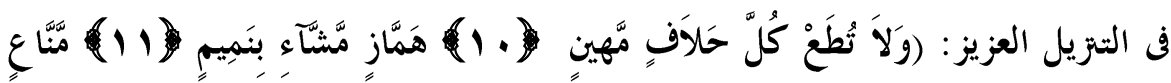

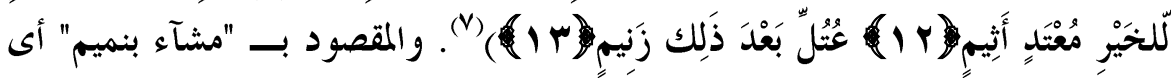

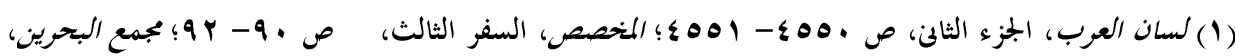

$$
\begin{aligned}
& \text { r II } / Y
\end{aligned}
$$

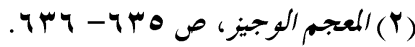

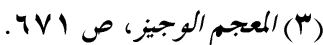

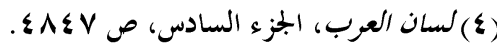

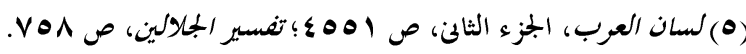

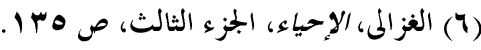

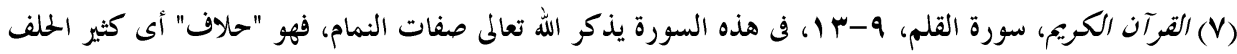

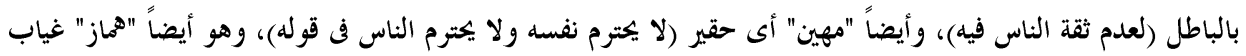


ساع بالكلام بين الناس على وجه الإفساد بينهم، أو الذى لا يتكم حديث(') وحذر

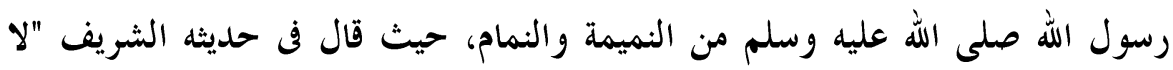

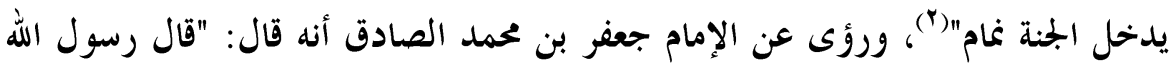

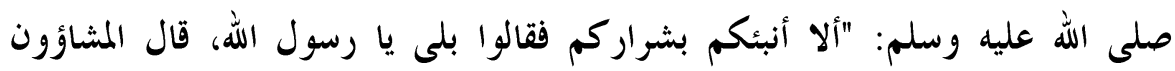
بالنميمة المفرقون بين الأحبة الباغون للبر آء الغيب" ("). أما فى اللغة المصرية القديمة عبر المصرى القديم عن النميمة والثرثرة والقيل والقال

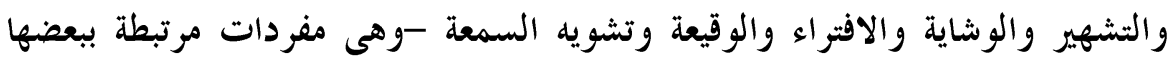

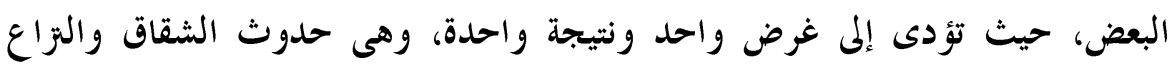

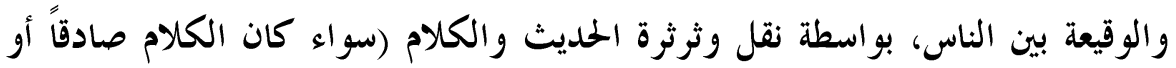

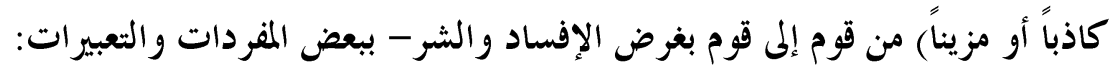

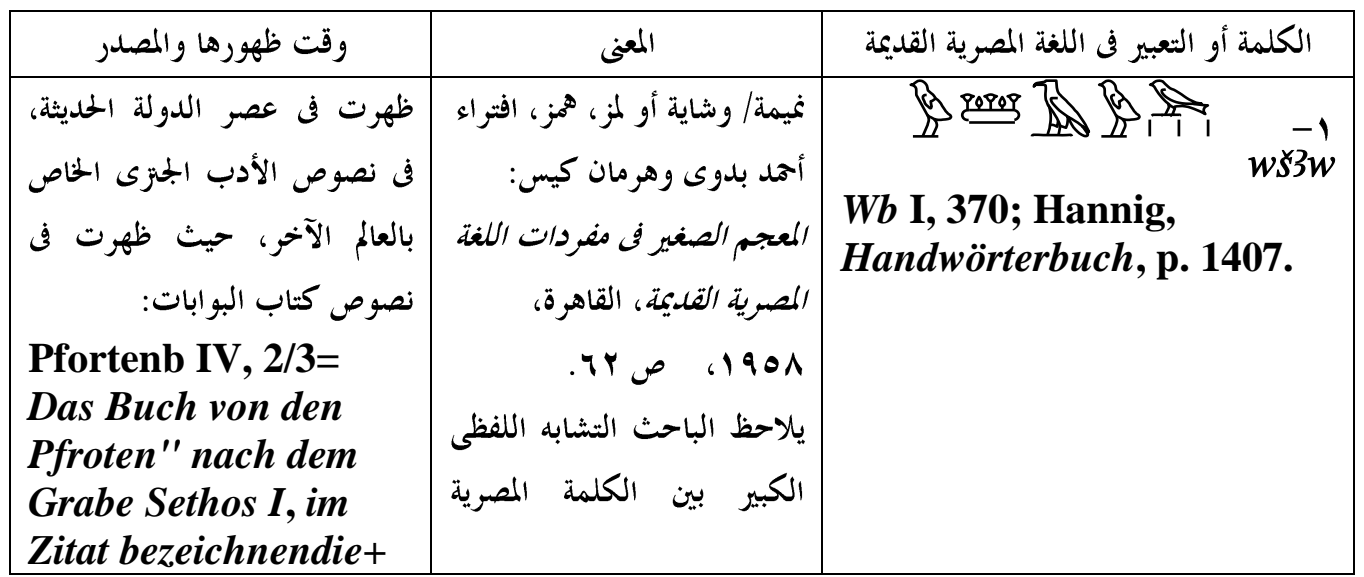

=أى مغتاب (أى يهمز الناس أو يغتاهم ويصيبهم بالقول والإشارة فل حضورهم وفى غيبتهم على حد سواء). وهو أيضاً.

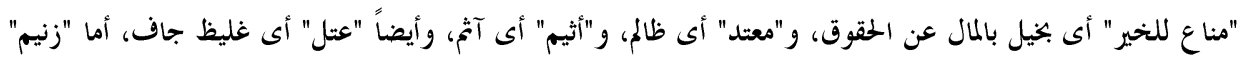

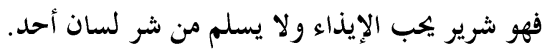

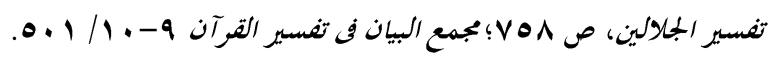

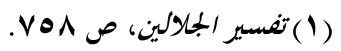

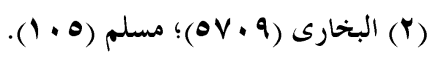

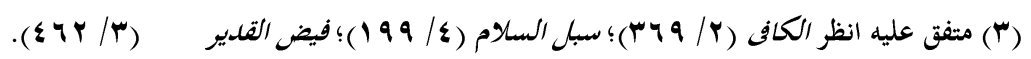




\begin{tabular}{|c|c|c|}
\hline $\begin{array}{l}\text { Abschnitte der } \\
\text { Publikation }\end{array}$ & 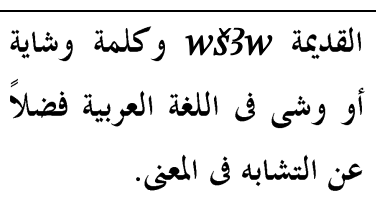 & \\
\hline 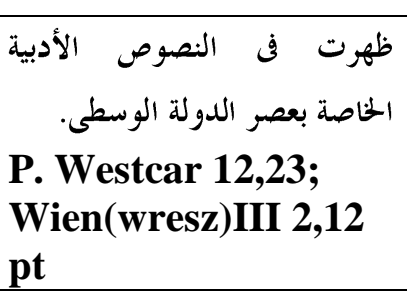 & 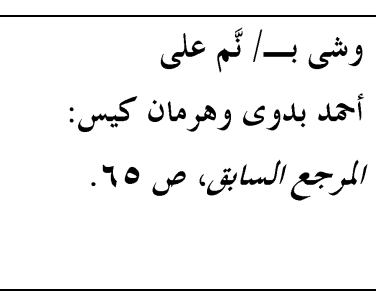 & $\begin{array}{l}\text { wtss (1) }{ }_{-\infty}^{8} \text {-r } \\
\text { Wb I 384, 2; Hannig, op. } \\
\text { cit., p. 1407. }\end{array}$ \\
\hline 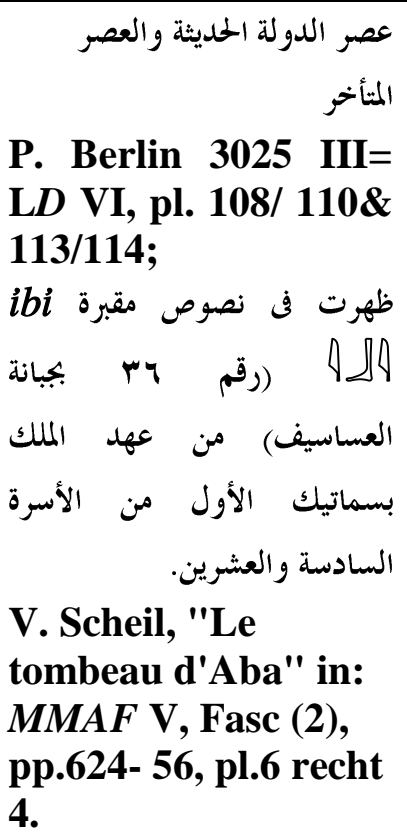 & نام، وشاء وقاع & $\begin{array}{l}w t s w \text { क } \\
\text { Wb I 384,3; Hannig, op. cit., } \\
\text { p. 1407. }\end{array}$ \\
\hline
\end{tabular}

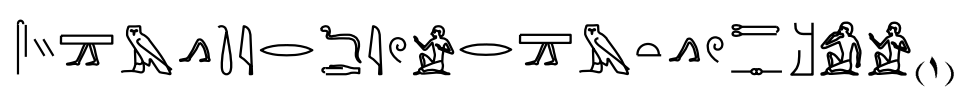

sy smti $r \underline{d} d$ iw.i $r$ گrm.t wts.i

لقد ذهبت لتقول، أنا سأذهب لوشى أو لأنم

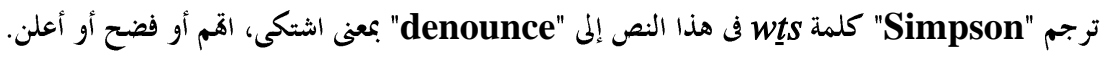

W. K. Simpson, The Literature of Ancient Egypt, An Anthology of Stories, Instructions, and Poetry, London, 1977, p. 30.

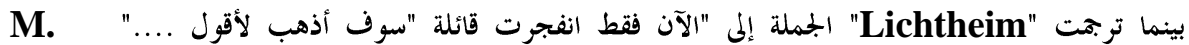

Lichtheim, Ancient Egyptian, A Book of Readings, vol. I, London, 1970, p. 222. 


\begin{tabular}{|c|c|c|}
\hline 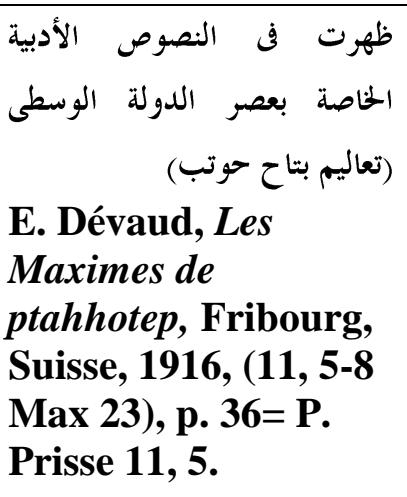 & 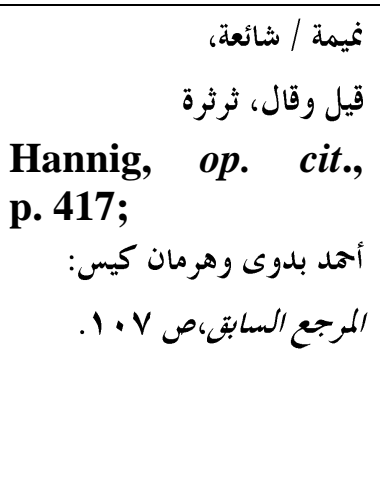 & 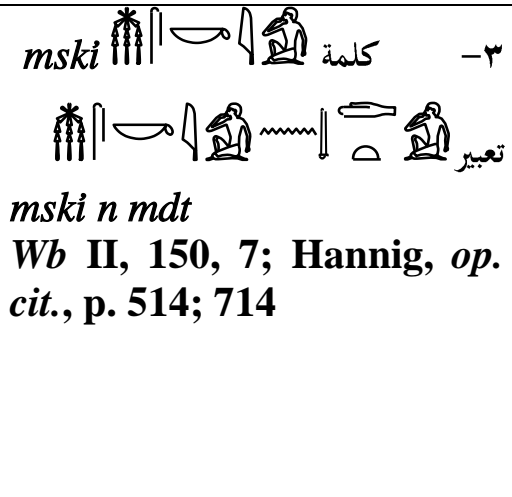 \\
\hline 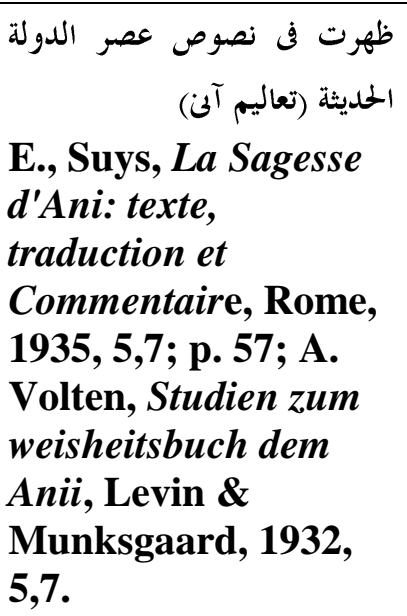 & أن التمدة/ قيل وقال & 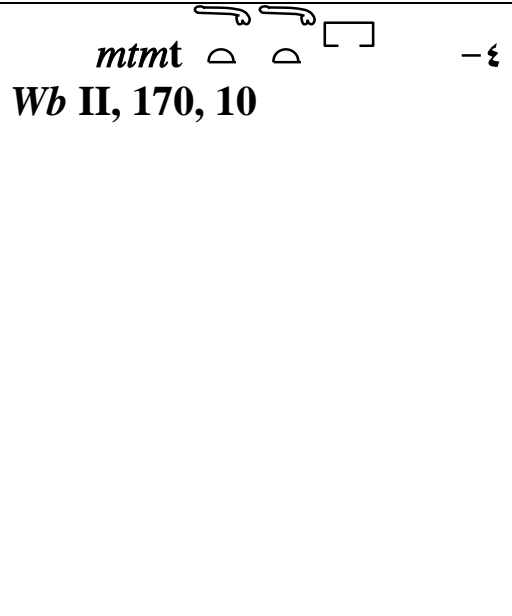 \\
\hline 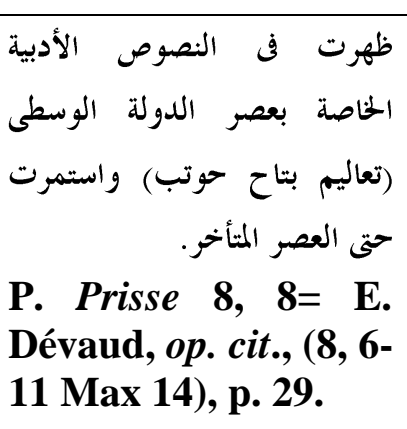 & 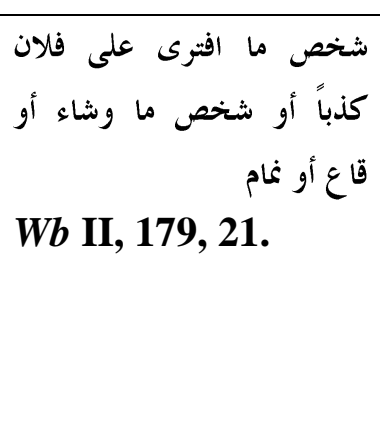 & $\begin{array}{l}m d w y=\text { की } \\
W b \text { II, 179, } 21 .\end{array}$ \\
\hline ظهرت في نصوص عصر الدولة & 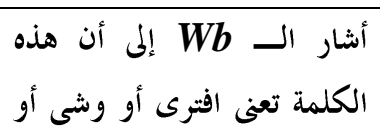 & $\begin{array}{l}n \underline{d} w i . t \simeq 4 \text { ฯ } \\
\text { Wb II, 377, } 17 .\end{array}$ \\
\hline
\end{tabular}




\begin{tabular}{|c|c|c|}
\hline $\begin{array}{l}\text { K. Sethe, Äegyptische } \\
\text { Lesestücke, Leipzig, } \\
\text { 1928, (19), 79, } 17 .\end{array}$ & 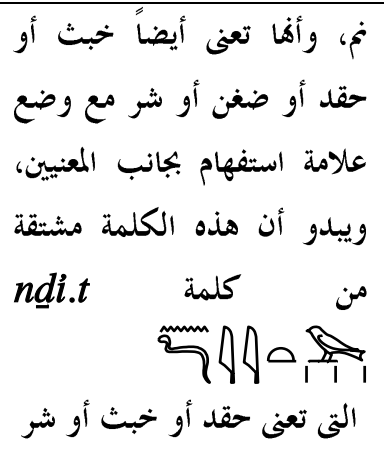 & \\
\hline $\begin{array}{l}\text { ظهرت في نصوص عصر الدولة } \\
\text { Urk, I, 78, 11. }\end{array}$ & 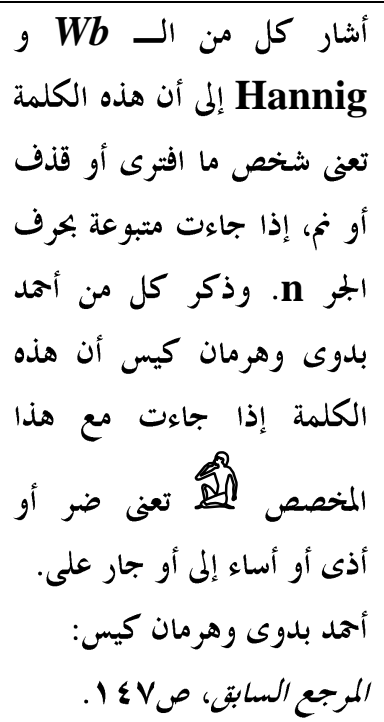 & $\begin{array}{l}\quad h m \text { 口 } \\
\text { Wb II, 489, 17; Hannig, } \\
\text { op.cit., p. 1407. }\end{array}$ \\
\hline $\begin{array}{l}\text { ظهرت هذذا المعنى في تعاليم آن من الدولة الحديثة. ع. Suys, } \\
\text { E. Sut. 1, 9, p. 3; A. } \\
\text { op. cit., 1, } \\
\text { Volten, op.cit., 1, 9. }\end{array}$ & 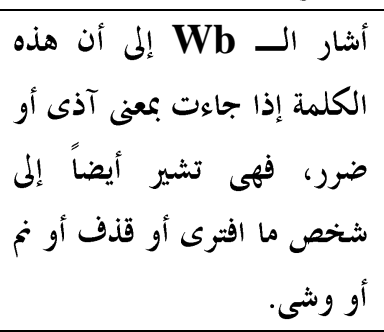 & $\begin{array}{l}\text { hdi } \times^{2} \oint_{-\wedge} \\
\text { Wb II, 213, 3; Hannig, } \\
\text { op.cit., p. 1407. }\end{array}$ \\
\hline 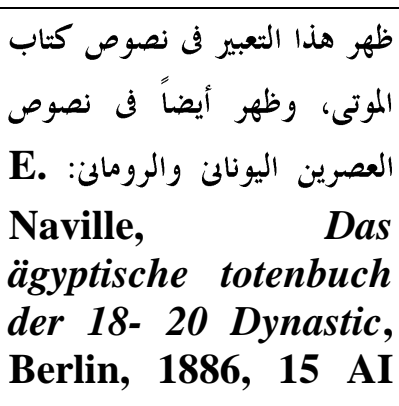 & 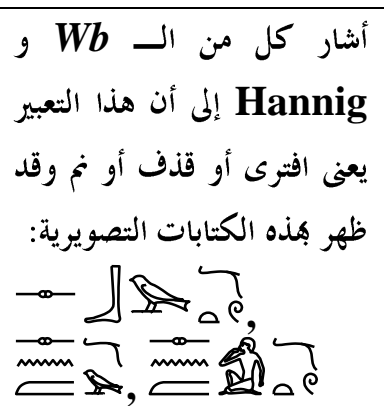 & 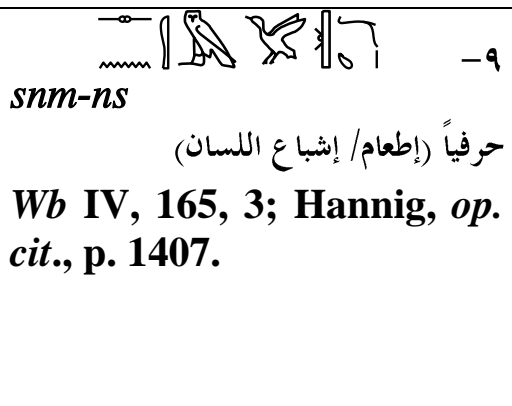 \\
\hline
\end{tabular}




\begin{tabular}{|c|c|c|}
\hline $\begin{array}{l}\text { 16; Edfou I, 521, } \\
\text { Dendara III, 556. }\end{array}$ & & \\
\hline ظشرت فل نصوص الأسرة الثامنة & حيمة/ القيل والقال & 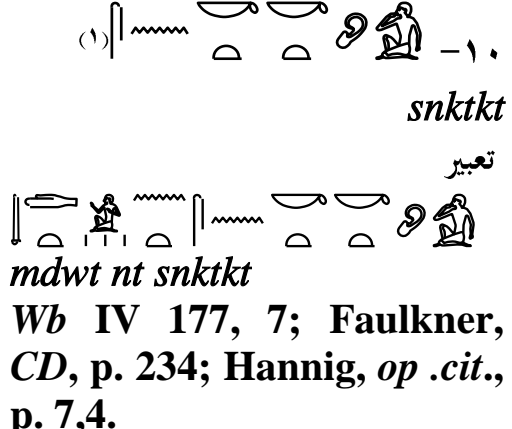 \\
\hline
\end{tabular}

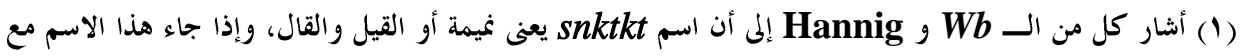
كلمة mdwt مكون تعبير "mdwt nt snktkt" الذى يعنى حديث النميمة أو القيل والقال، ويلاحظ الباحث

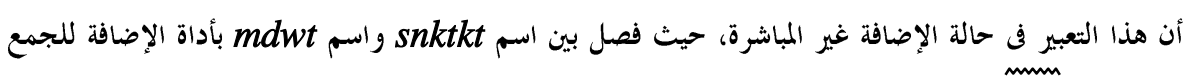
المؤنث nt ه ه ، حيث جاءت هذه الأداة وتحددت حسب المضاف (الاسم الأول) وليس حسب المضاف إليه،

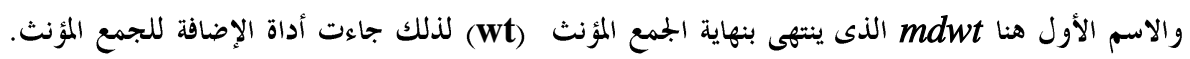

Wb IV, 177, 7; Hannig, op .cit., pp. 714- 715; $=\quad$ انظر

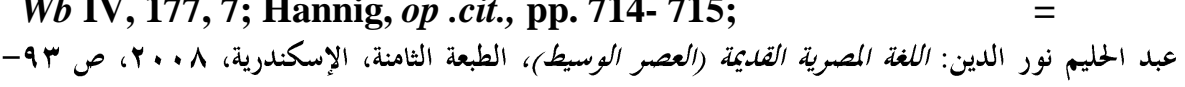
؛ 9 纟

A. H., Gardiner, Egyptian Grammar, Begin and introduction to the Study of Hieroglyphs, third edition, London, 1973, § 85- 86; pp. 65- 66; Abd Elmohsen Bakir, "Varia Grammatica", in: JEA 52, 1966, pp. 35- 36; W. Schenkel, "Director und indireter Genitiv", in: ZÄS 88, 1962, pp. 58- 66.

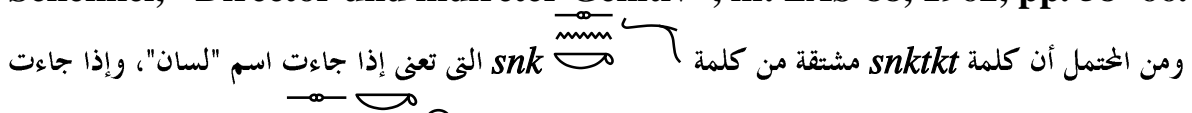

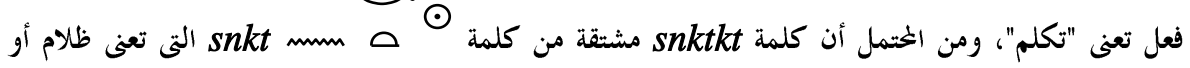

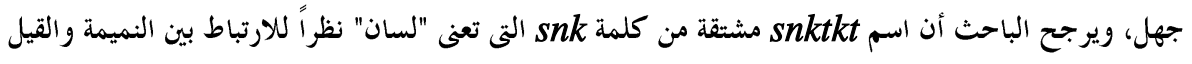

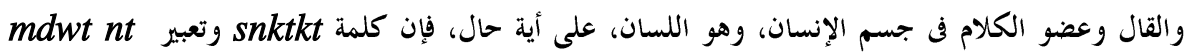
snktkt

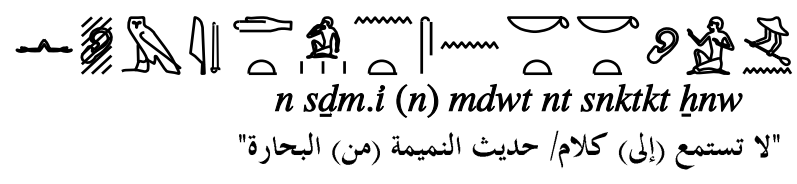




\begin{tabular}{|c|c|c|}
\hline 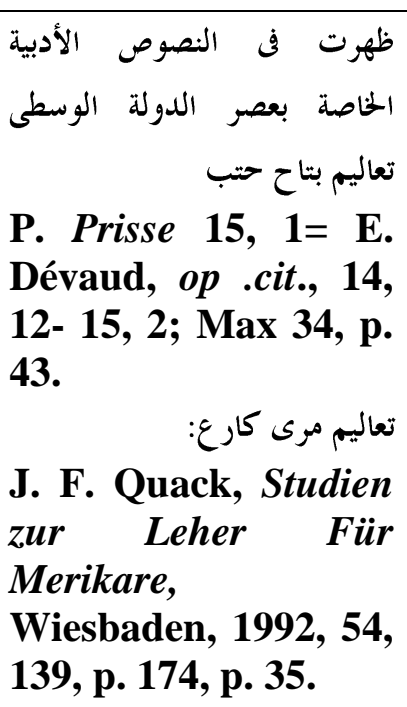 & نغام/و & 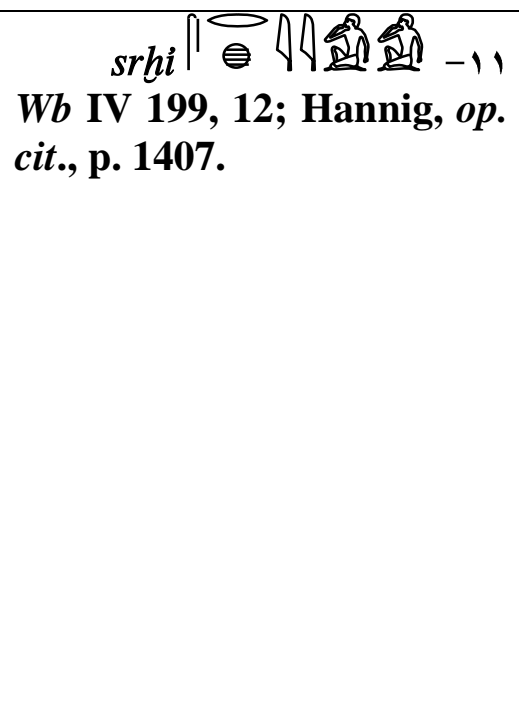 \\
\hline 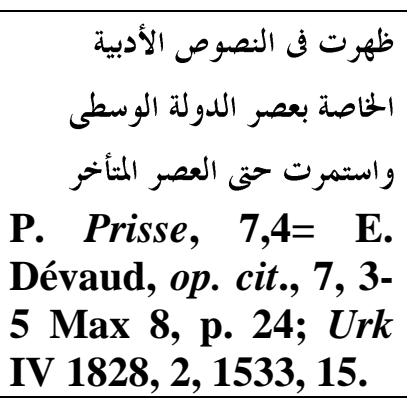 & 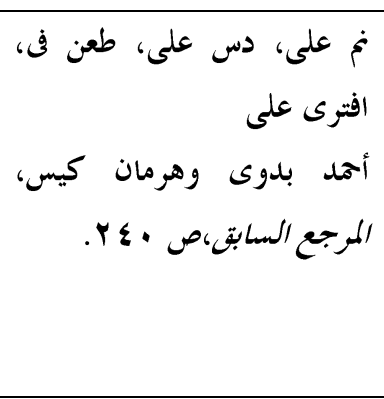 & 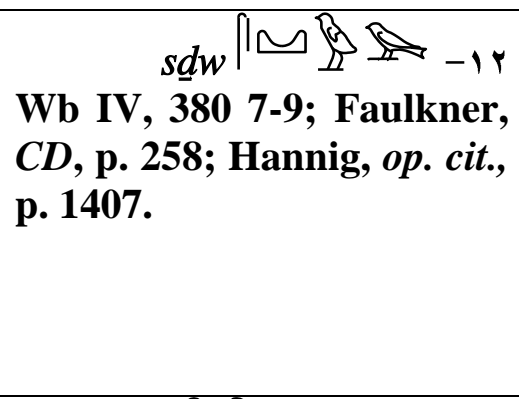 \\
\hline 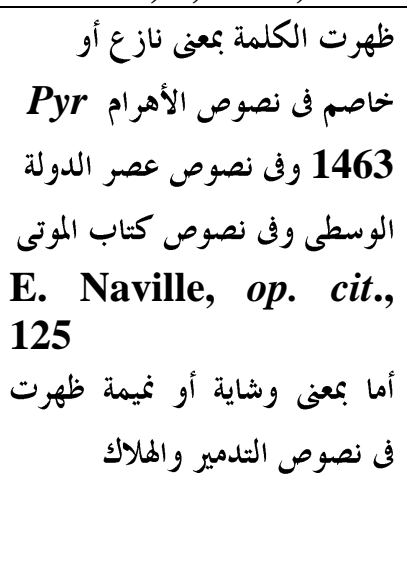 & 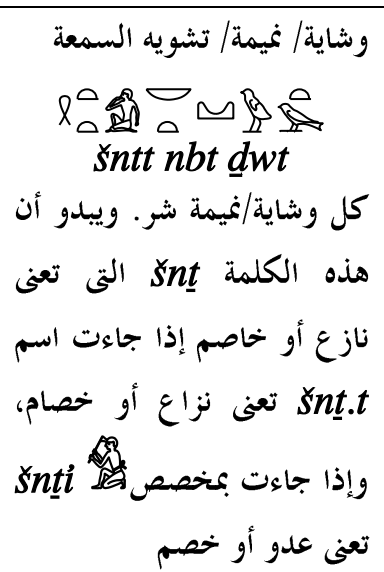 & $\begin{array}{l}\text { Snt.t } \\
\text { Wb IV 520, 1, 2; } \\
\text { Hannig, op. cit., p. 1407. }\end{array}$ \\
\hline 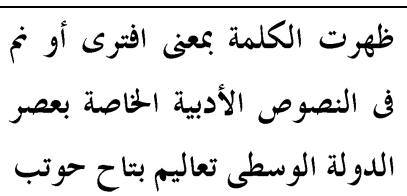 & 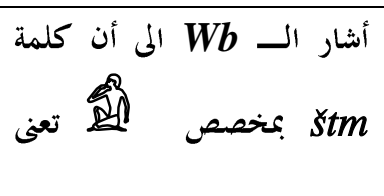 & $\begin{array}{l}\text { stm } \\
\text { Wb IV, } 557,13,14\end{array}$ \\
\hline
\end{tabular}




\begin{tabular}{|c|c|c|}
\hline $\begin{array}{l}\text { P. Prisse II, 13, = E. } \\
\text { Dévaud, op. cit., p. } \\
\text { 37, Max 25 } \\
\text { وتعاليم مرى كارع } \\
\text { J. F. Quack, op. cit., } \\
\text { p. } 200 \text { (147). }\end{array}$ & 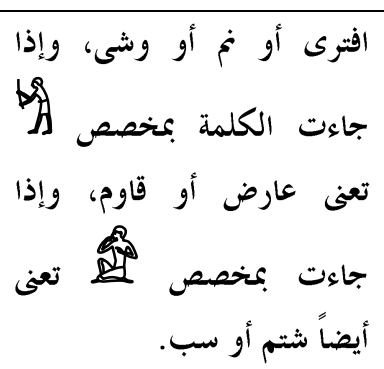 & $\begin{array}{l}\text { Hannig, op. cit., } 1407 \\
\text { Faulkner, } C D, \text { p. } 273\end{array}$ \\
\hline 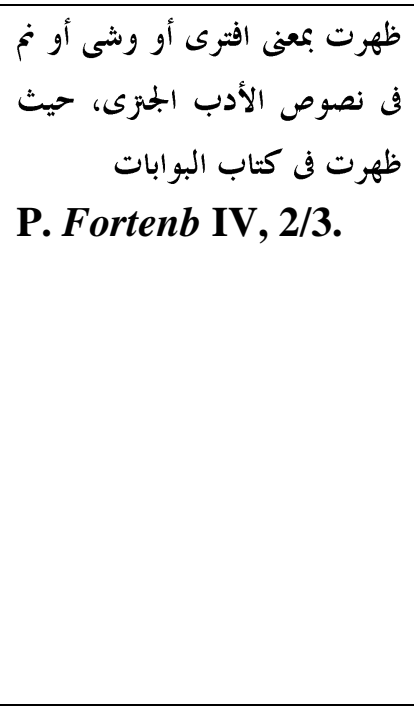 & 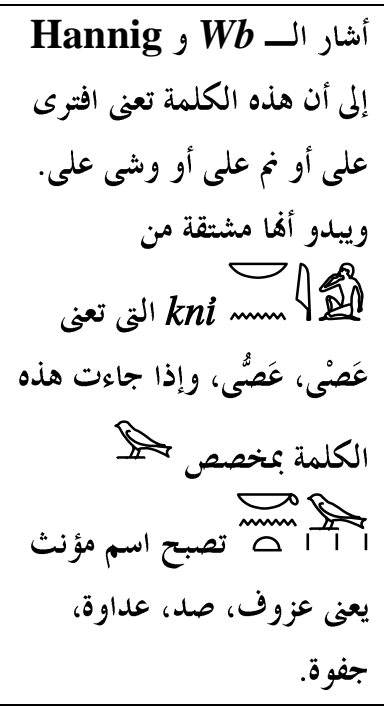 & $\begin{array}{l}\text { kniw mm } \\
\text { Wb V, 132, } 1 \text {, } \\
\text { Hannig, op. cit., p. } 1407 .\end{array}$ \\
\hline $\begin{array}{l}\text { ظهرت في نصوص عصر الدولة } \\
\text { K. Sethe, op. cit., } \\
\text { (19), } 79 \text { (16). }\end{array}$ & 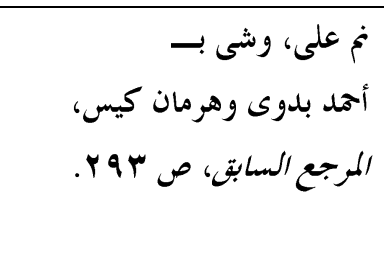 & 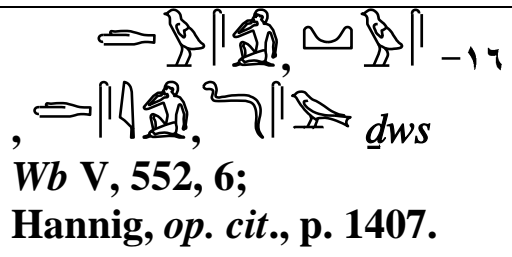 \\
\hline
\end{tabular}

وسوف يتناول الباحث فن هذا البحث التعبيرات والمفردات الدالة على النميمة في

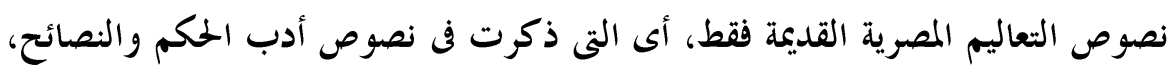

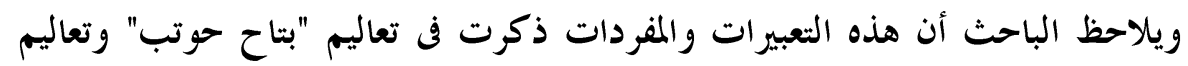

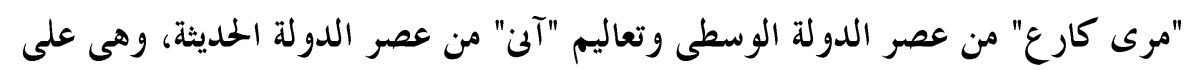

(1) أشار كل من أمد بدوى وهرمان كيس أن اسم

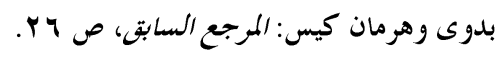




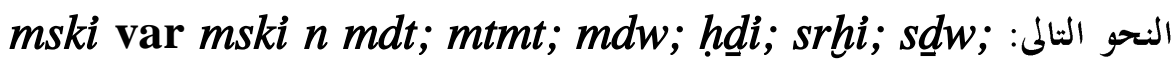

وسوف يبين الباحث من خلال دراسة وتحليل هذه التعبيرات والمفردات

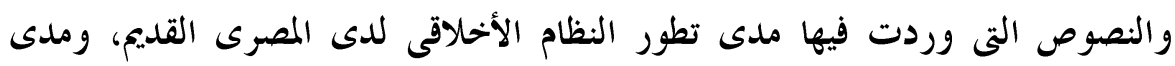

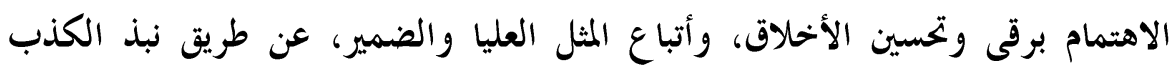

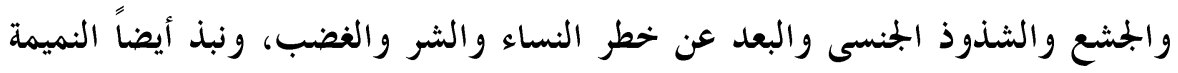

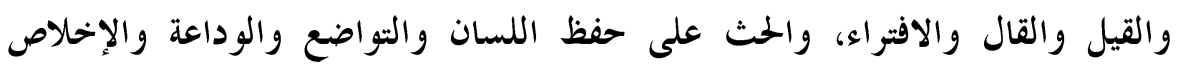

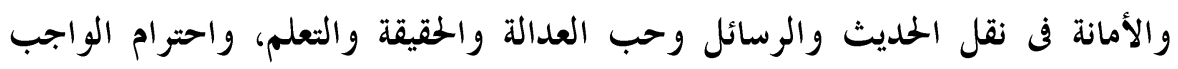

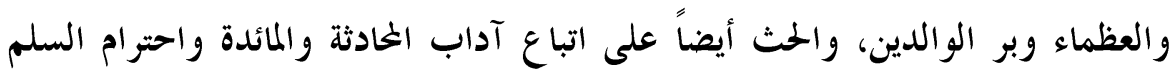

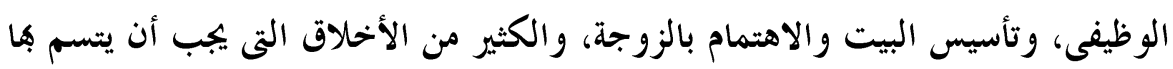
الإنسان.

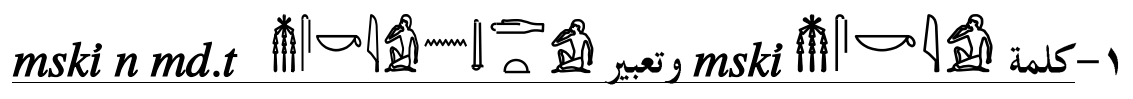

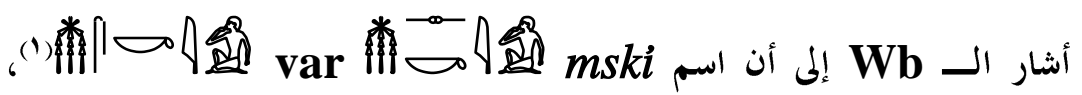

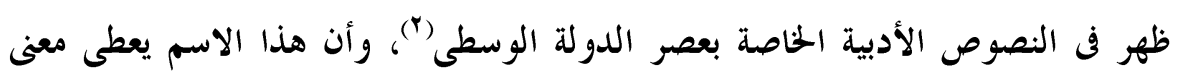

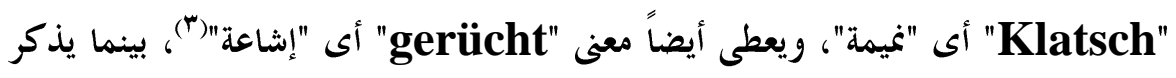
"Gardiner"

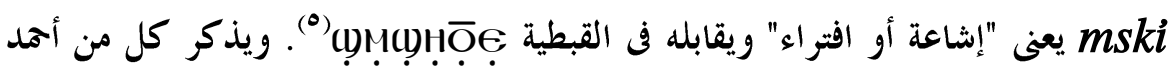

(1) $W b$ II, $150,7$.

(2) P. Prisse II, 5; P. Brit. Mus. 10371/ 10435 (e 1- e2) = E. Dévaud, op. cit., II, 5-8 (Max 23); p. 36 (350); G. Jóquier, Le Papyrus Prisse et ses variantes, Paris, 1911, pl. XXXVI, 11, 5; Z. Žaba, Les Maximes des Ptahhotep, Prague, 1956, 11, 5, p. 44.

(3) $W b$ II, 150, 7.

(4)A. H. Gardiner, Egyptian Grammar, Begin and Introduction to the Study of Hieroglyphs, Third edition, London, 1973, p. 570.

(5)D. Meeks, Annee Lexicographique Egypte Anceinne, tome 1, 1977, Paris, 1980, 77. 1878, p. 173. 


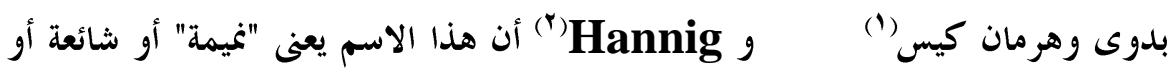
قيل وقال أو ثرثرة، إذا جاء مع اسم

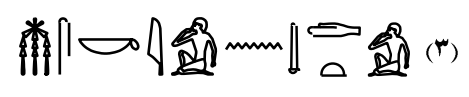

\section{mski $n$ md.t}

ويعنى اسم md.t "حديث أو كلام"(\&)، لذلك يمكن تربمة هذا التعبير حرفياً إلى

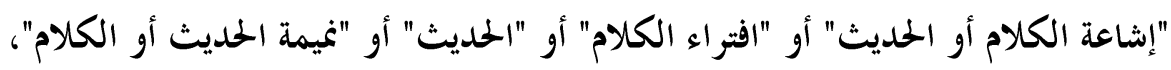

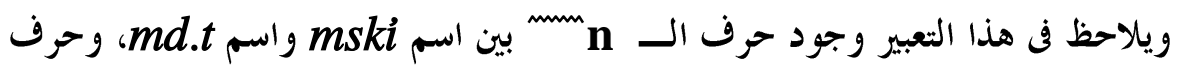
الــ n هنا أداة إضافة للمفرد المذكر، فالتعبير في حالة الإضافة غير المباشرة

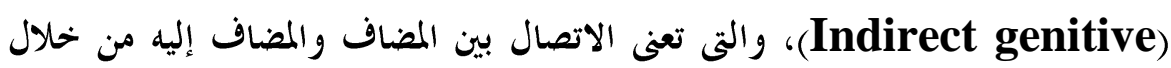

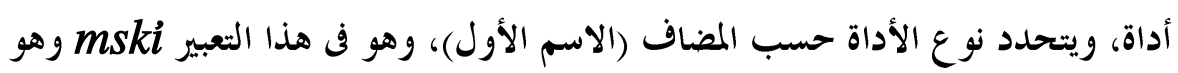

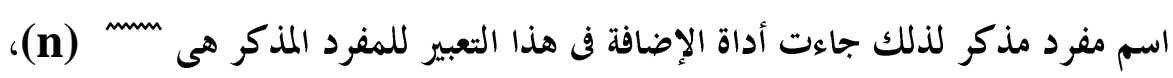

$$
\text { ومن المعروف أن الإضافة هى ضم وإسناد اسم إلى آخر (•). }
$$

أما "Faulkner" أشار إلى أن اسم mski إذا جاء مع اسم md.t يعنى Slander (?) من المعالن، فهى تعنى "تشهير أو افتراء أو وشاية أو وقيعة"، وهى معادئ معانى قريبة من تعريف فعل النميمة.

$$
\text { (1) أهد بدوى وهرمان كيس: المرجع السابق، صV • 1. }
$$

(2)R. Hannig, op. cit., p. 714.

(3)P. Prisse, 11, 5= E. Dévaud, op. cit., p. 36 (350) (Max 23).

(4) Wb II, 181; R. O. Faulkner, A concise dictionary of Middle Egyptian, Oxford, 1964, p. 122.

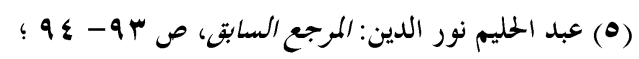

A. H. Gardiner Egyptian Grammar $3^{\text {rd-ed }}$, § 85- 86; 65- 66, Abd El Mohsen, Bakir, JEA, 52, 1966, pp. 35-36; W. Schenkel, ZÄS,88,1962,pp5866.

(6) R. O. Faulkner, $C D$, p. 118. 
ويرى الباحث أن اسم mski من الختمل أنه مشتق من فعل msi

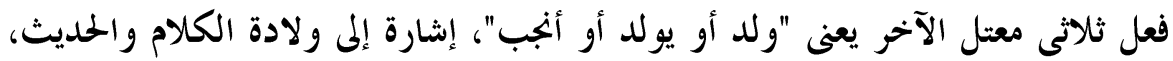

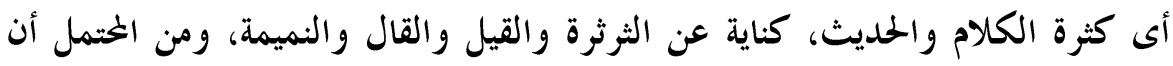

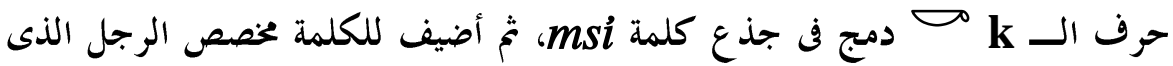

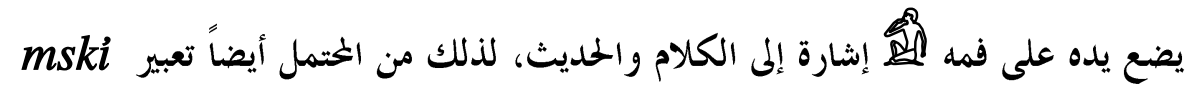

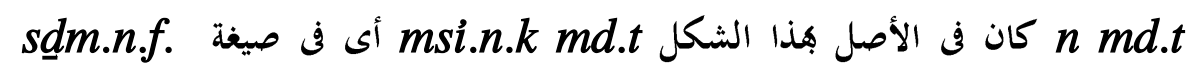

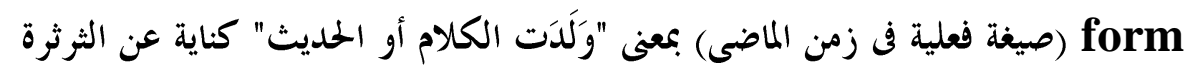
والقيل والقال والنميمة، ثم تم إدغام ودمج الضمير المتصل للشخص الثم الثالن المفرد المذكر

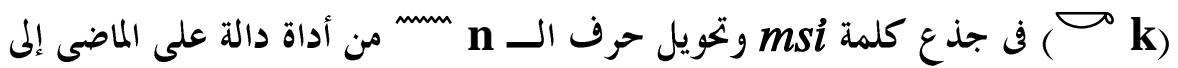

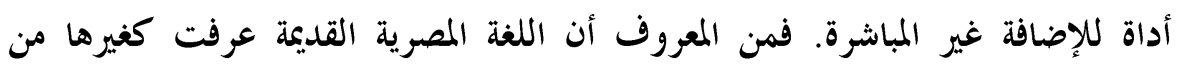

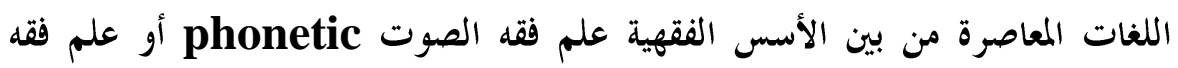

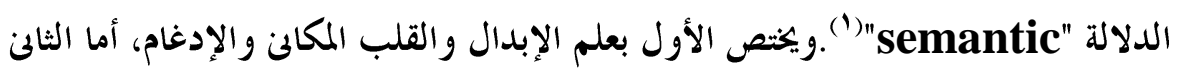

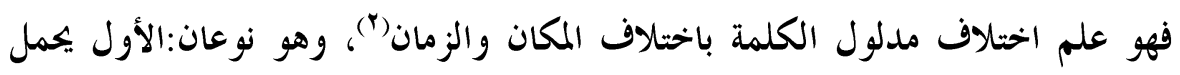

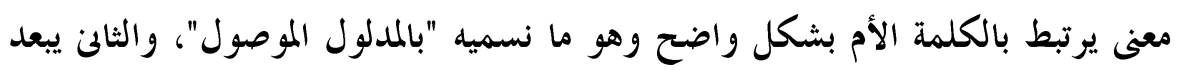

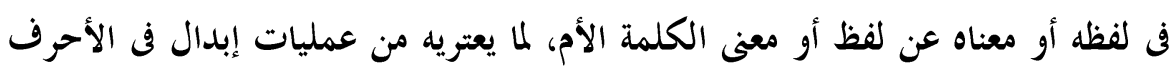

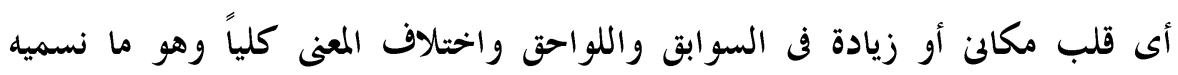

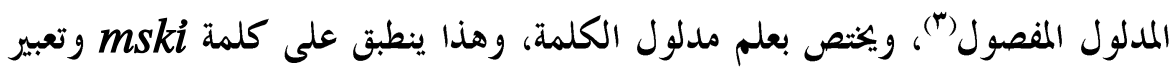
mski n md.t الذى ورد في تعاليم بتاح حوتب بمعنى نيمة.

\footnotetext{
$(11,5)$

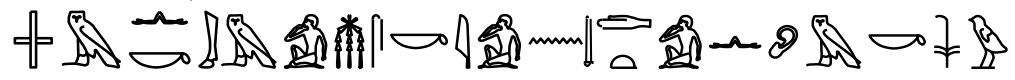

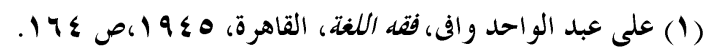

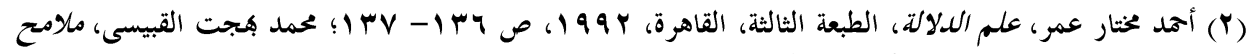

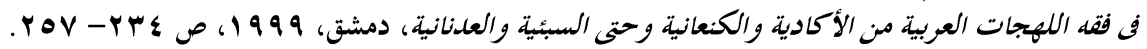

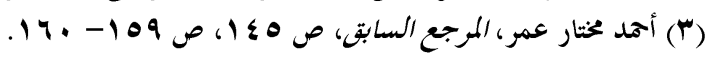




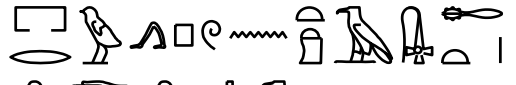

$$
\begin{aligned}
& \text { I) } \\
& \text { Q mun } \\
& \theta_{\infty}^{\circ} 80_{0}
\end{aligned}
$$

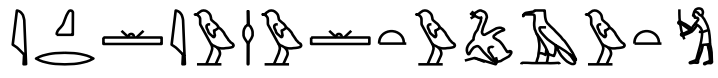

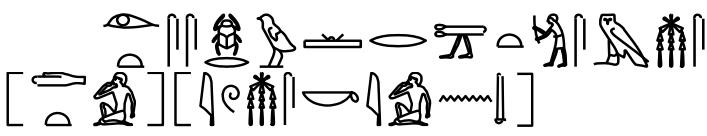

$$
\begin{aligned}
& \text { 口是 }(11,8) \text { \& }
\end{aligned}
$$

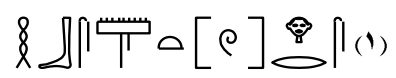

imi .k whm mski $n$ md.t $n$ sdm.k sw prw pw $n$ t3-h̆t $(11,0)$ whm mdt m33 n sdidm.n.st r-t3 $m \underline{d d}$ rs-sy mk.... hft hr.k rh $(11,7) i k r$ iw wd.tw tiswt irt.s shprw r ittt.s ms[dt] [iw mski $n \mathrm{~m}] d t(11,8)$ mi hp mk sswn rswt pw ḥbs $t[w]$ hr.s

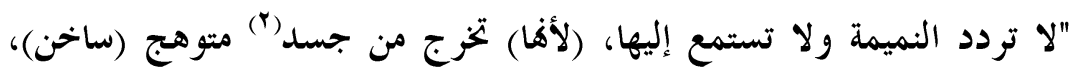

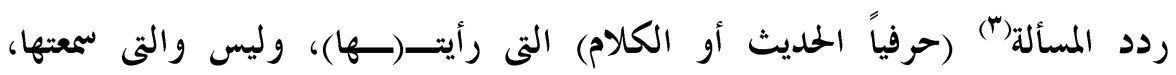

(1)P. Prisse II, 5-8 (Max 23)= E. Dévaud, op. cit., (350), p. 36; Z. Žaba, op. cit., p. 44.

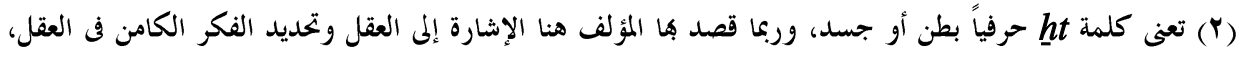

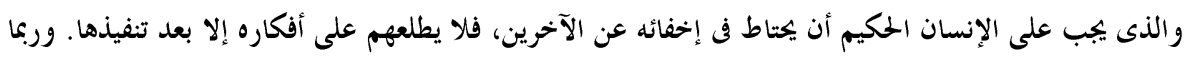

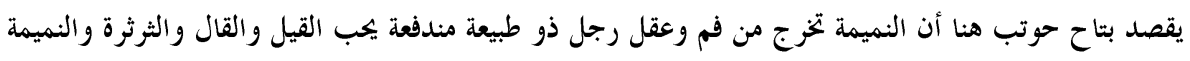

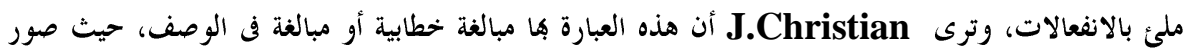

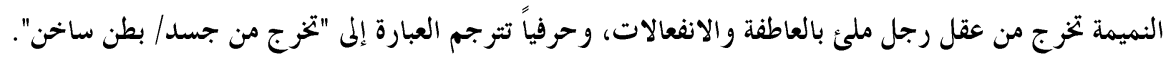

J. Christian, L'Enseignement du sage égyptien ptahhotep, Le plus ancient Livre du monde, Paris, La Maison de vie, 1993, p. 111.

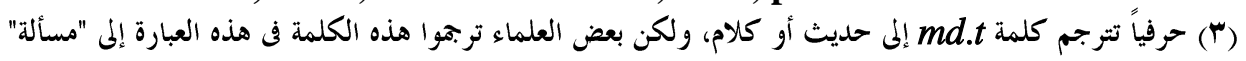

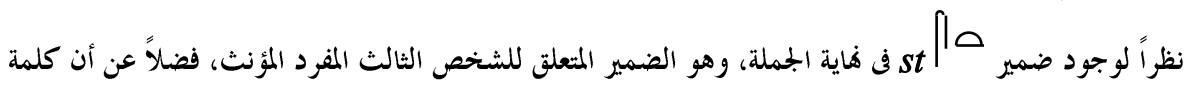
كلمة مؤنث تنتهى بتاء التأنيث. 


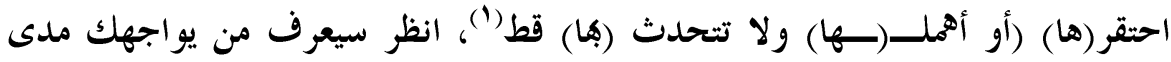

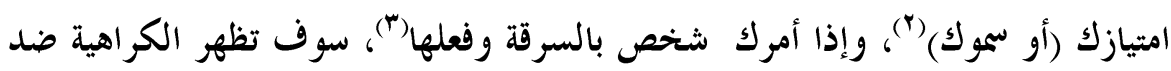

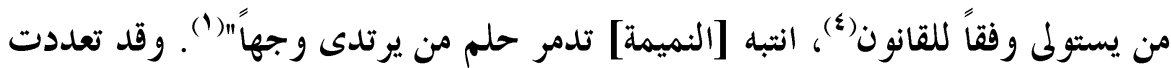
تراجم الباحثين لتعبيز

=W. K. Simpson,The literature of Ancient Egypt,London,1977,p. 168;

كلير لالويت: نصوص مقدسة ونصوص دنيوية من مصر القدية، ترجمة ماهر جويجاتى، الجلد الأول، القاهرة، - L

rss-sy (1) الكلمة

A. Gardiner, "Die Erzählung de sinune und die Hirtengeschichte" in: A Erman, Literarische texte des mittleren Reiches, Hieratische Papyrus aus den königlichem Mussem zu Berlin Bd v, Leipzig, 1909, p. 153.

$$
\text { Urk IV 519, 8; 945, 4; }
$$$$
\text { وتعنى هذه الكلمة تماماً أو كلياً انظر: }
$$

A. Gardiner, The Admonitions of Egyptian Sage, Leipzig, 1909, 6, 5.

A. Gardiner, op.cit., p. 153; وتأتى بعد النفى بمعنى مطلقاً أو أبداً أو كلية، انظر W. Wreszinski, Der Papyrus Ebers, Leipzig, 1913, 37, 75; 14; 9, 16; Urk IV, 115, a; 107, 4, 3; A. Gardiner, Egyptian Grammar $3^{\text {rd-ed }}, \quad \S 205$, p. 155.

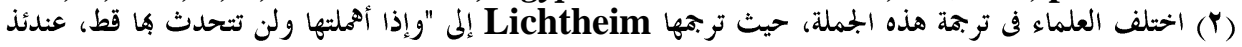

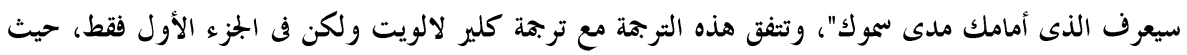

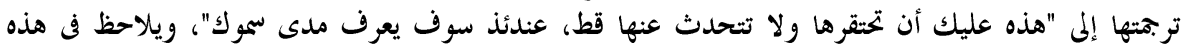

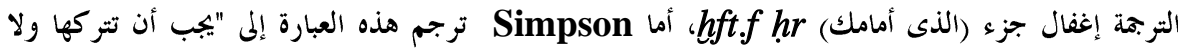

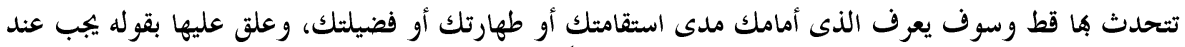

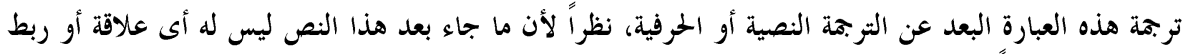

M. Lichthem, op. cit., p. 70;

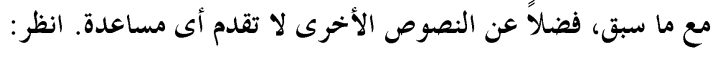

W. K. Simpson, op. cit., p. 168, Note (46);

$$
\text { كلير لالويت: المرجع السابق، ص q هب؛ }
$$

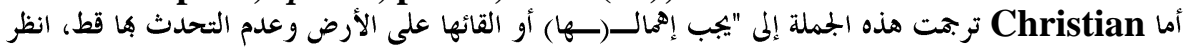

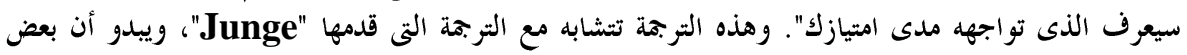

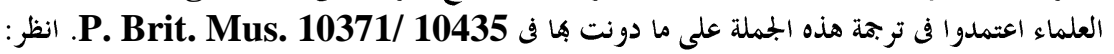

J. Christian, op .cit., pp. 111- 112; F. Junge, Die Lehre Ptahhoteps und die tugenden der ägyptischen welt, Göttingen,2003,p.197.

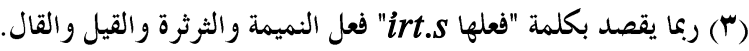

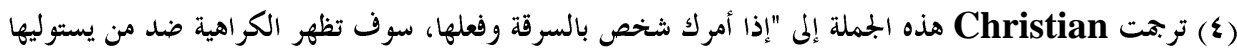

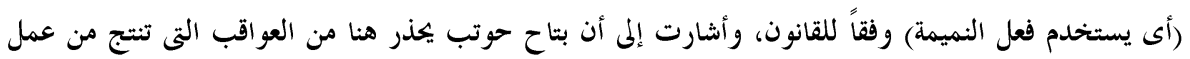


حيث تربمه Erman إلى "Frivolous Speeches" (")، أى "الأحاديث التافهة"، وتعطى كلمة "Frivolous" العديد من المعاني منها "تافه أو عابث أو طائش

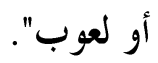

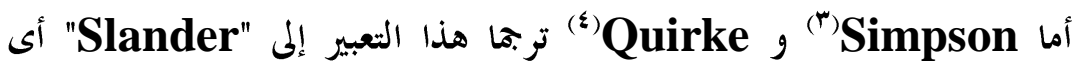
"تشهير أو افتراء أو وشاية أو وقيعة أو تشويه سمعة". أما Christian JACQ

وتفعل النيمة، وهذه العواقب سوف تكون شديدة جداً وفقاً للوائح والقوانين ضد النيمة والتشهير التى تضرر J. Christian, op.cit.p. 112

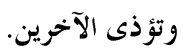

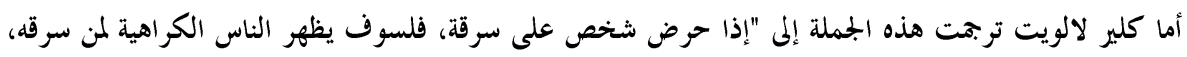

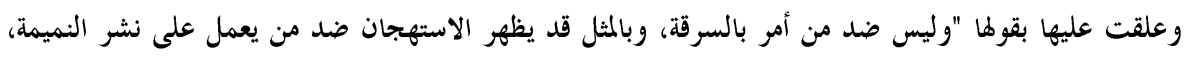
وليس ضخد من هو مصدر هذه الأكذوبة".

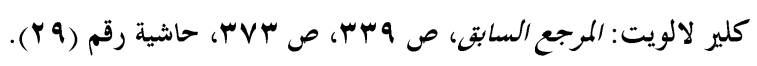

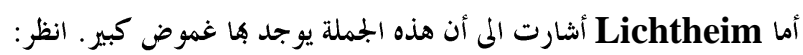

M. Lichtheim, op. cit., p. 79, Note (40).

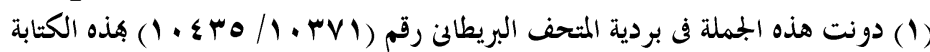

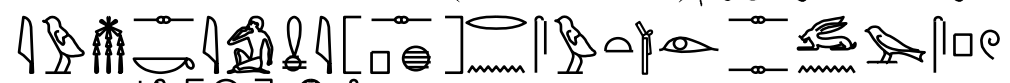

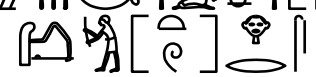

iw mski mi [sp-sn] n rswt sswn.s pw eḩ (tw) hr.s

$$
\text { "النيمة مثل الحلم [مرتان] يجب معاقبتها ومحاربتها" }
$$

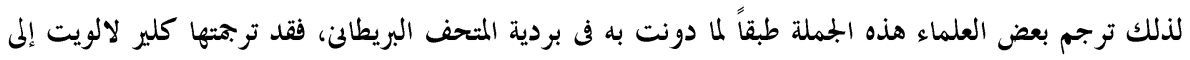

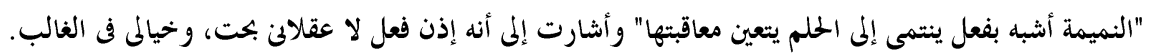

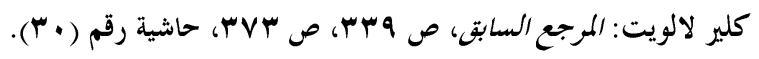

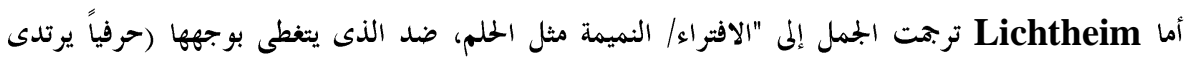

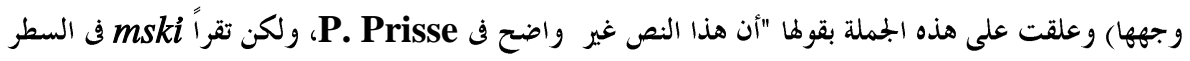

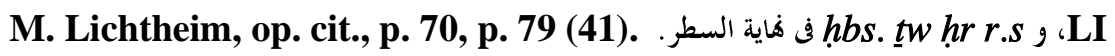

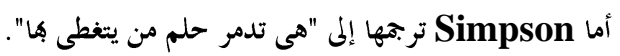

W. K. Simpson, op .cit., p. 168.

(2)A. Erman, The Ancient Egyptians, A source book of their writings, translated by A. M. Blackman, London, 1978, p. 61.

(3)W. K. Simpson, op .cit., p. 168.

(4)S. Quircke, Egyptian Literature 1800 B.C., Question and Reading, London, 2004, p. 95. 
أشارت إلى أن هذه النصيحة من نصائح "بتاح حوتب" تشير إلى رفض الإشاعات

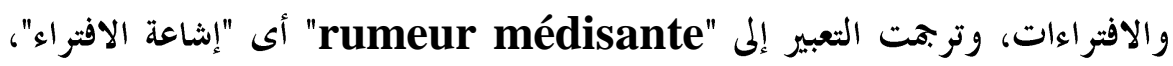
وذكرت أن هذا التعبير يشير إلى افتراء الكلام، وأنه غالباً يشير إلى "Calomine" ألى "إنى

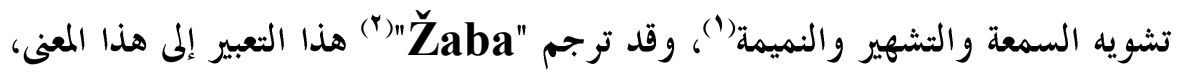

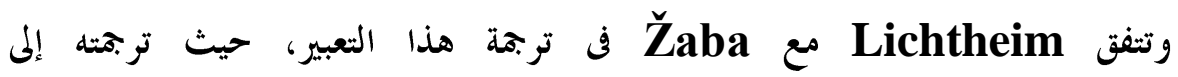
"Calumny" Nachrede Verbreiten"

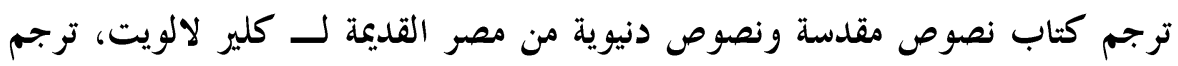
التعبير إلى "نميمة"(•) - (ن)

ويلاحظ الباحث من خلال التراجم المختلفة والمتعددة التى قدمها الباحثين لتعبير mski n md.t بغرض التشويه والوشاية والوقيعة.

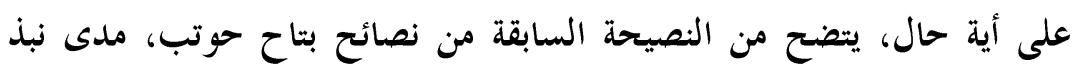

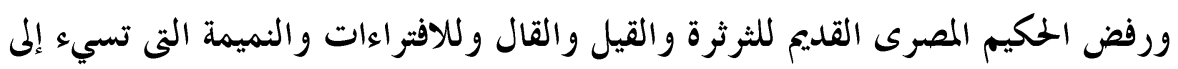
الآخرين وتؤدى إلى تشويه السمعة والوقيعة بين الناس. ويرى "Junge" أن هذه وله

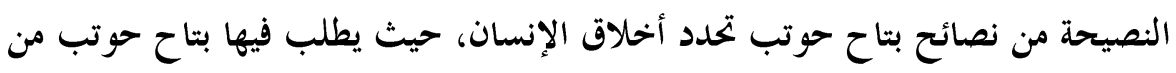

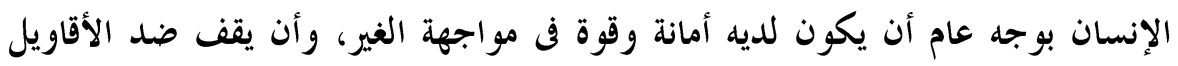

(1)J. Christian, op .cit., pp. 111- 112.

(2)Z. Žaba, op. cit., p. 90.

(3) M. Lichtheim, op .cit., p. 70.

(4) J. Junge,op. cit., p. 179.

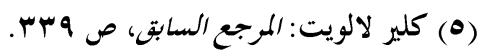

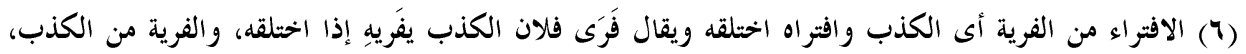

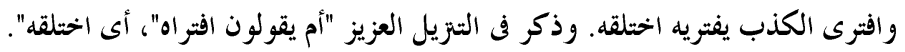

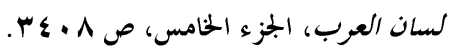


والثرثرة والحديث السيء والنميمة والافتراء، والتى تصدر دائماً من عقل (جسد/ بطن)

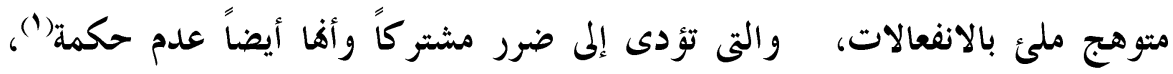

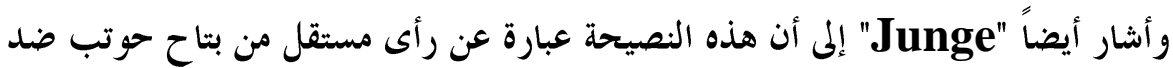

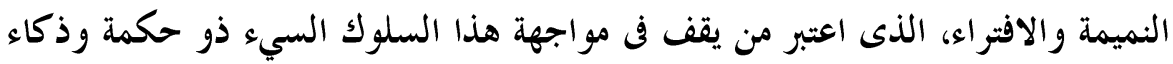

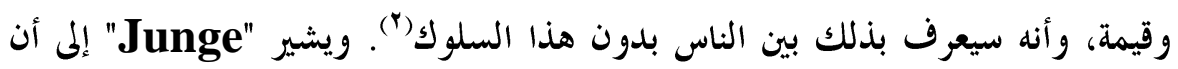

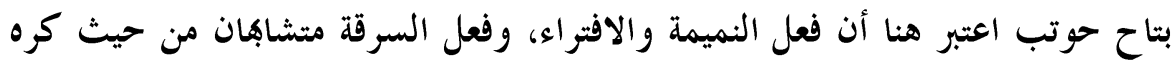

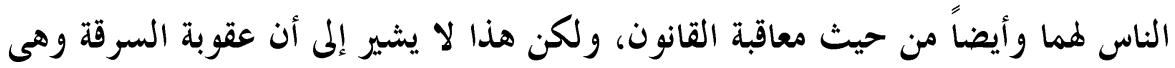
جذع الأنف هى عقوبة فعل النميمة والافتراء، ولكن يقصد أن النميمة والافتراء يشبهان السرقة من الناحية الاجتماعية من حيث كره الناس لمما، وليس من الناحية القانونية،

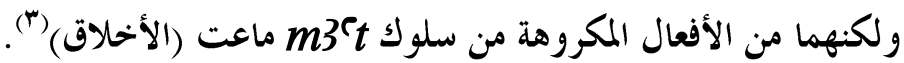

لذلك اعتبر بتاح حوتب أن الرزانة والهدوء فى الحديث من صفات الرجل الخحترم القدير ذو الحكمة الذى يوقره ويقدره الناس.

"إذا كنت رجلاً قديراً، فاعمل على أن يخشاك الناس، بسبب علمك و كلامك رك (₹) " لكن تجنب الإساءة أو الرد بكلام حاد. الهادئ

$$
\text { mtmt } \square \stackrel{\square}{\square} \square-r
$$

يذكر الـ Wb أن اسم mtmt ظهر في نصوص عصر الدولة الحديثة، وأنه

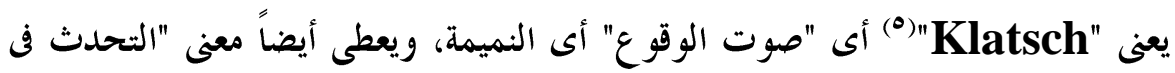

(1)F. Junge, op. cit., p. 53.

(2)F. Junge, op. cit., p. 58.

(3)Ibid., p. 58, p. 92.

(4)E. Dévaud, op. cit., 11, 12- 12, 6 (Max 25), p. 37; Z. Žaba, op. cit., pp. 4545- 46; pp. 90- 91; M. Lichtheim, op. cit., p. 70; W. K. Simpson, op. cit., p. 168;

(5)Wb II, 170, 10.

$$
\text { كلير لالويت: المرجع السابق، ص qبr }
$$


شؤون الناس" و"القيل والقال" وتشنيع الناس، ولم يذكر هذا الاسم في قاموس

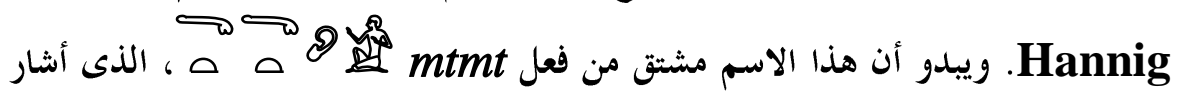

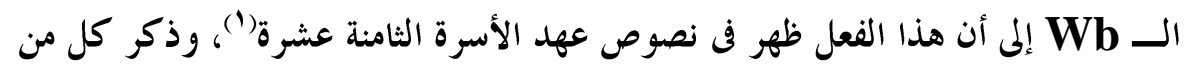

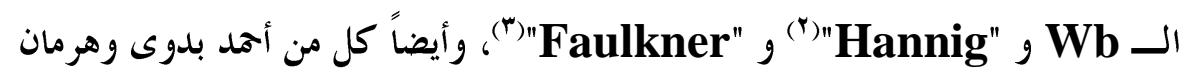
كيس (q) أن هذا الفعل يعنى ناقش أو حاور أو تبادل الآراء:

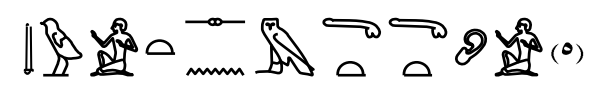

mdwt sn m mtmt

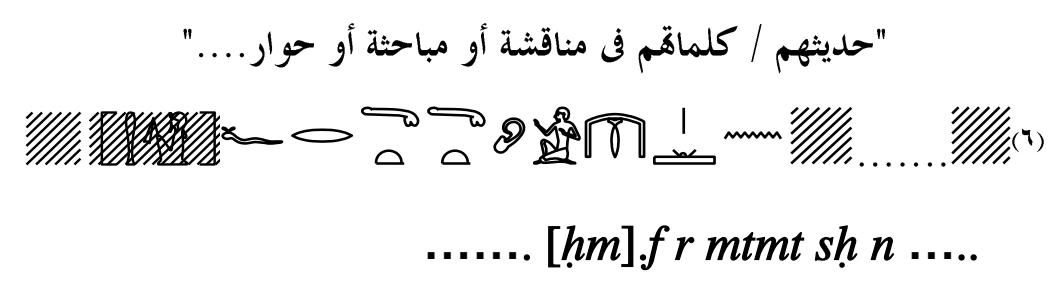

"[جلالته]] [نش/ تبادل الآراء من أجل النصيحة أو المشورة"

أما اسم

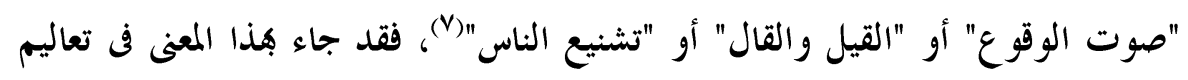

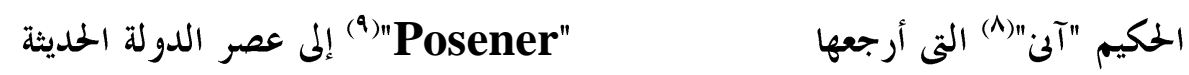

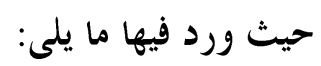

(1) $W b$ II, 170, 8-9.

(2) R. Hannig, Handwörterbuch, p. 366.

(3) R. O. Faulkner, CD, p. 121. (צ) (أهم بدوى وهرمان كيس: المرجع السابق، ص 9.

(5) Urk IV, 364, 14.

(6) Urk IV, 434, 10.

(7)Wb II, 170, 10.

(8) Wb, Belegstellen II, p. 249.

(9)G. Posener, "Les richesses in connues de la literature égyptienne (Recherches Littéraires I)", in: RdE 6, 1951, p. 42. 


$$
\begin{aligned}
& \left\{=0 \mathrm{P} \mathrm{H}_{\mathrm{H}}\right.
\end{aligned}
$$

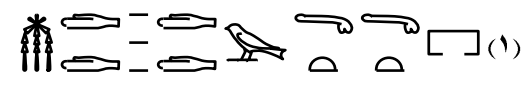

kd n.k pr gm.k ini.n msdi mtmt ${ }^{(๗)}$

"شيد لك متزل، وإن وجدت، ابتعد عن أو تجنب الكره والنميمة أو القيل

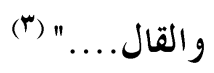

وقد تعددت تراجم الباحثين لهذه العبارة التى وردت في تعاليم آنى، حيث ترجمها "E. Suys"

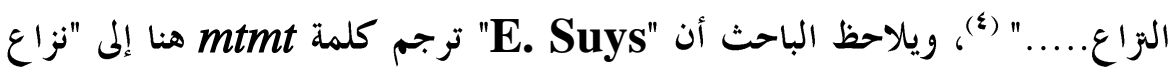

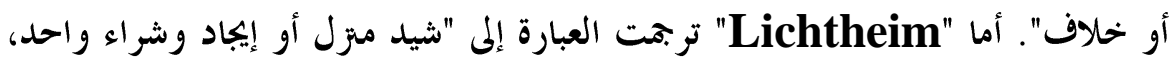

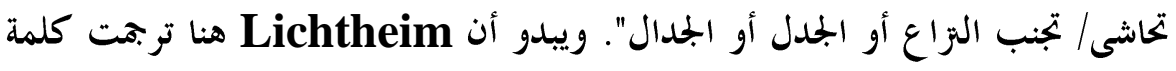
msdi ماهر جويجاتى الذى ترجم كتاب "نصوص مقدسة ونصوص دنيوية" لـ كلير لالويت،

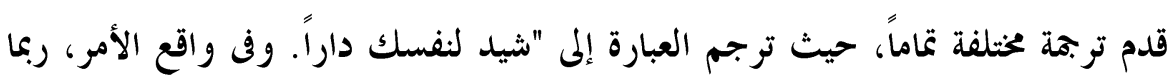

(1)E. Suys, la Sagesse d'Anii: texte traduction et commentaire, Analecta orientalia 2, Rome 1935, p. 57.

$$
\begin{aligned}
& \text { msdi (T) }
\end{aligned}
$$

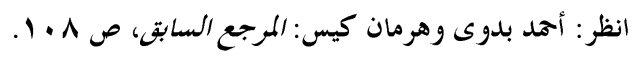

$W b$ II, 154, R. O. Faulkner, CD, p. 118; H. Lesko, A Dictionary of Late Egyptian, vol. I, California, 1982, p. 244; A. H. Gardiner, Late Egyptian Miscellanies Bruxelles, 1937, (10), 1, 8 = P. Lansing 1, 8; A. H. Gardiner, Late Egyptian Stories, Bruxelles, 1932, (1), 7, 4; (1) 5, 12; Urk IV 461, 5; 758, 9; Urk VII 14, 7; Urk IV 969, 3.

(3) E. Suys, op. cit., p. 57.

(4)Ibid., p. 57.

(5)M. Lichtheim, op .cit., p. 139. 
انتهيت إلى اكتشاف أن متزلا قد يجلب عليك الكراهية أو المشاحنات.....". أى أنه

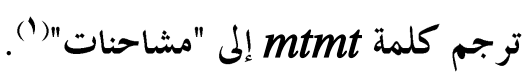

ويلاحظ الباحث أن التراجم التى قدمها الباحثين لكلمة mtmt التى وردت في

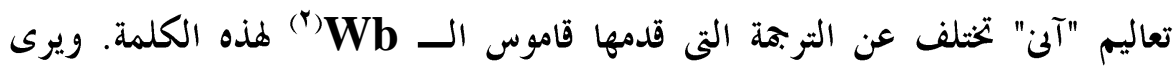

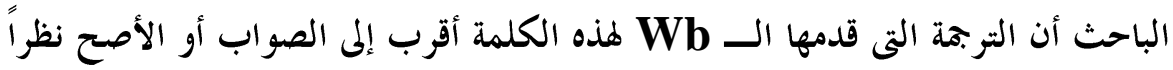

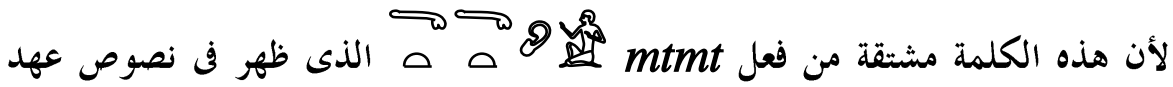

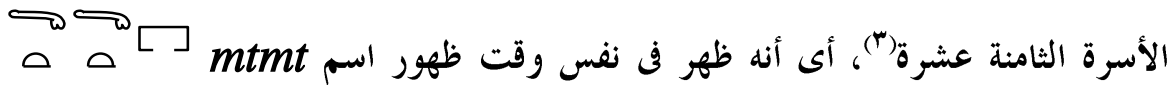

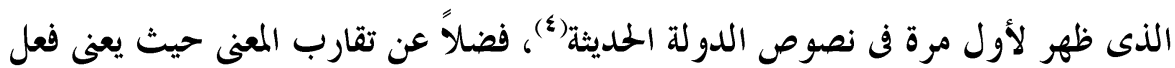

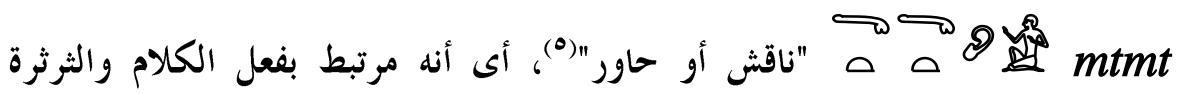

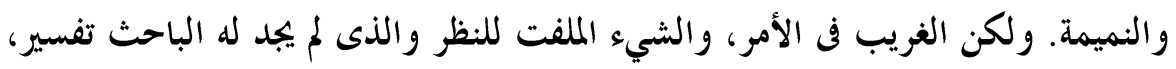

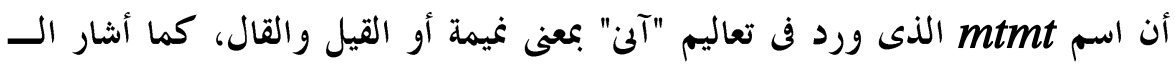

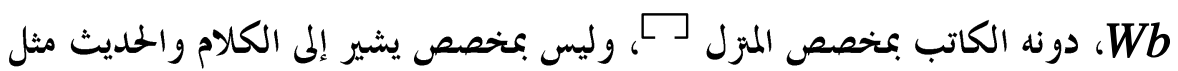

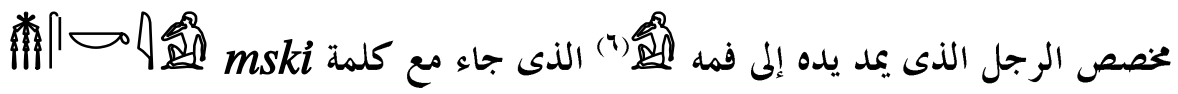
التى تعنى نيمة أو افتراءs)

(2) $W b$ II, 170, 10.

(1) كلير لالويت: المرجع السابق، ص9 ؛ ؟.

(3) $W b$ II, 170, 8-9.

(4) $W b$ II, 170, 10.

(5) R. Hannig, Handwörterbuch, p. 366; R. O. Faulkner, CD, p. 121;

أحد بدوى وهرمان كيس: المرجع السابق، ص 9 . 1.

(6) A. H. Gardiner, Egyptian Grammar $3^{\text {rd }}$-ed, Sign-list A2, p. 442.

(7) Wb II, 150, 7; D. Meek, Alex, 77. 1878, p. 173; R. Hannig, Handwörterbuch, p. 714;

$$
\text { أمد بدوى وهرمان كيس: المرجع السابق، ص V• ا. }
$$




\section{$m d w y \|=$ PAl}

أشار الـ Wb إلى أن كلمة $m d w y$ أو

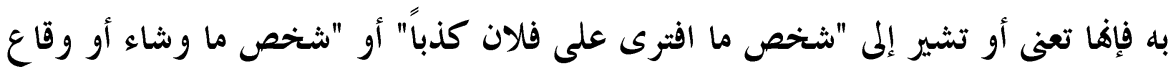

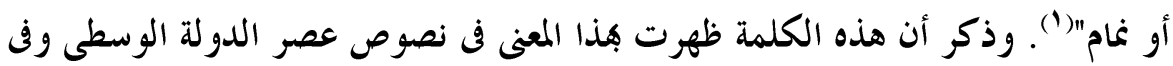
نصوص العصر المتأخر ("). ويبدو أن كلمة mdwy مشتقة من الفعل الثلاثى المعتل الآخر

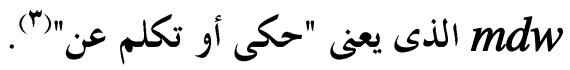

على أية حال، وردت كلمة mdwy بالمعنى السابق في تعاليم بتاح حوتب:

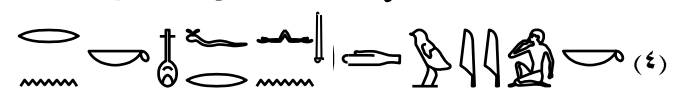

\section{$r n . k n f r n n m d w y . k$}

"ستكون سمعتك (حرفياً اسمك) طيبة دون أن تنم (حرفياً دون أن تتكلم عن)"

ويرى الباحث أن تعبير nn mdwy.k الذى على وزن

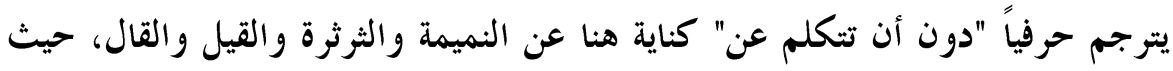

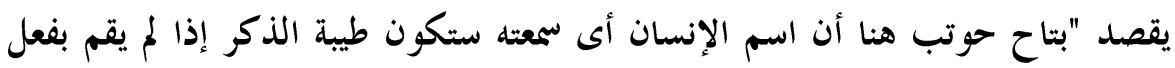

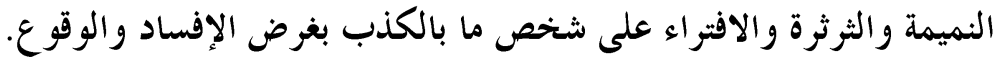

(1) $W b$ II, 179, 21.

(2) Wb II, Belegstellen, p. 262 (21)= Louvrea 84, 8, äth.

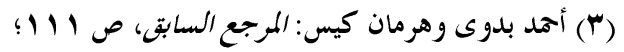

R. O. Faulkner, $C D$, p. 122.

(4)E. Dévaud, op. cit., p. 29, 8, 8= (8, 6- 11 Max 12)= P. Prisse 8, 8; Z. Žaba, Žaba, op. cit., 8, 8 (240), p. 35.

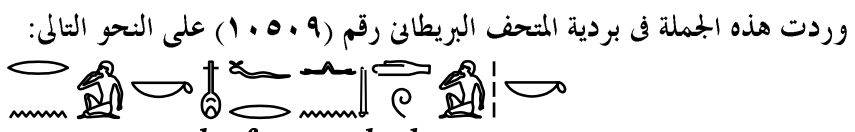

$r n . k n f r n n m d w . k$

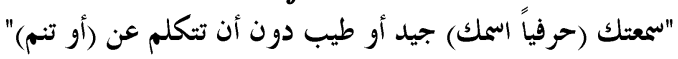

E. Dévaud, op. cit., p. 29; Z. Žaba, op. cit., 240, (L 2), p. 35.

ويشير Žaba إلى أن كلمة mdw.k فـ هذه الجملة صفة أو نعت. انظر:

Ibid., p. 134. 
ويلاحظ الباحث أن تعبير mdwy.k الذى على وزن Sdm.k يسبقه أداة النفى

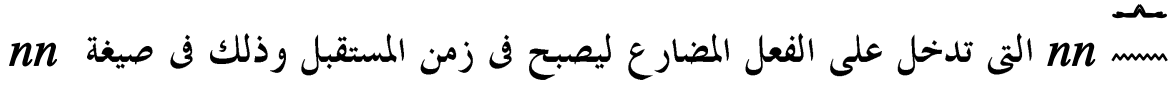
أ المفعول به الثانى لتعبير rn.k "اسمكك" الذى على وزن أيضاً

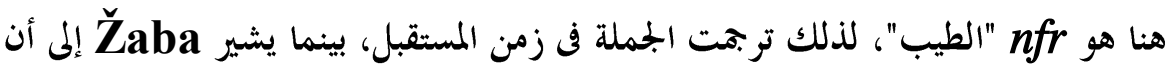

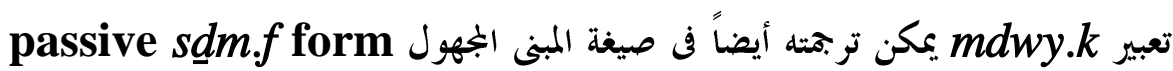

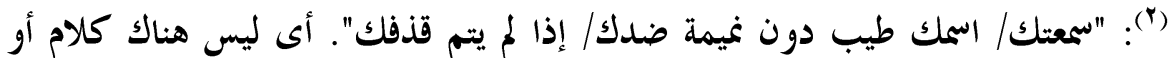

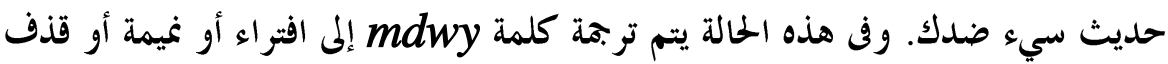

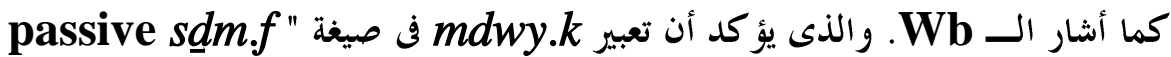
أن كلمة mdwy تنتهى بحرف Ahy (y)، ومن المعروف أن من حالات البناء

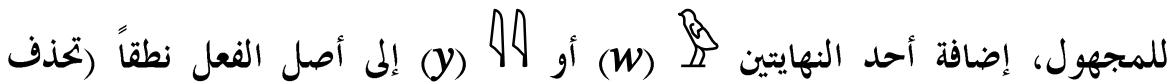

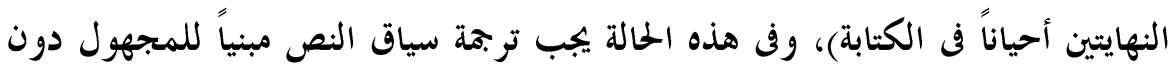
وجود إشارة مكتوبة ملحقة بالفعل (ل).

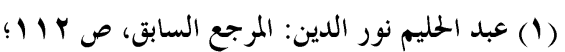
A. H. Gardiner, Egyptian Grammar $3^{r d}$-ed, $\S 105$, pp. 80-81, $\S 457=$ pp. 377378; B. Gunn, Studies in Egyptian Syntax, Paris, 1924, pp. 195-96, pp. 119126.

(2)Z. Žaba, op. cit., p. 134.

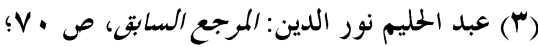

A. H. Gardiner, Egyptian Grammar $3^{r d}$-ed, § 419- § 424, pp. 337- ; L. Depuydt, "Zum Passive in Ägyptislen", in: Orientalia 62, 1993,328-75 
لذلك ترجم كل من "Westendorf

"سيكون اسمك طيب (حرفياً جميل) دون أن تنم أو إذا لم يكن هناك نيمة أو أفتراء

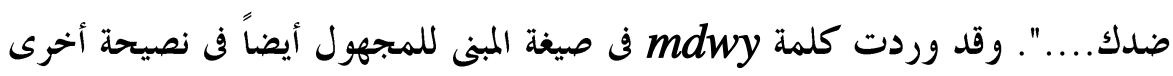
من نصائح بتاح حوتب حيث ورد هـا ما يلى: ولى

象

$m(w) d y w^{(\mathfrak{s})}[n] r m \underline{n} n b t$

"لا تقذف/ لا تنم [إلى] أى شخص/(ه) (حرفياً) لا تنكلم عن أى شخص"

وقد تعددت تراجم الباحثين لكلمة "mdwy" التى وردت في تعاليم بتاح حوتب،

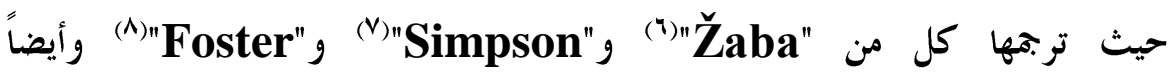

(1)W. Westendorf, Der Gebrauch des Passivs in der Klasischen Literatur der Ägypter, Berlin, 1953, p. 64.

(2)H. Kees, "Ägypten", in: Handbuch der Altertumswissenschaft, III. A bteilung, I. Teil, 3. Band, Kulturgeschichte des alten Orients 1, München 1933, p. 193.

(3)E. Dévaud, op. cit., p. 24; Z. Žaba, op. cit., p. 28; P. Prisse, 7, 4 (159).

الصيغة الفعلية الخاصة التى تستخدم بعد فعل النفى أو النهى m(w)dyw (q)

"negatival Complement"

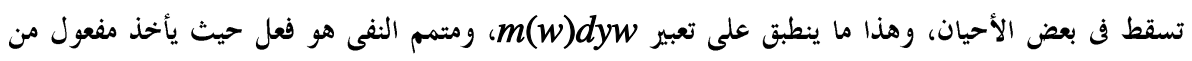

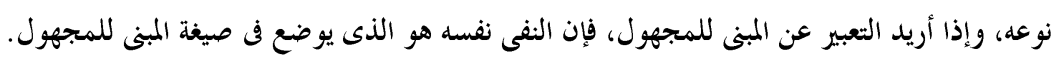

A. H. Gardiner, Egyptian Grammar, $3^{\text {rd }}$-ed, § 341, p. 261.

ويشير Žaba إلى أن m(w) dyw تعطى هنا معنى غيمة أو افتراء أو قذف.

Z. Žaba, op. cit., p. 124.

(5)M. Lichtheim, op. cit., p. 65; Z. Žaba, op. cit., p. 77.

(6)Z. Žaba, op. cit., p. 81.

(7) W. K .Simpson, op.cit, p. 165.

(8) John L., Foster, The Maxims of ptah-hotep, Toronto, 1977, p. 40. 
"Quirke"

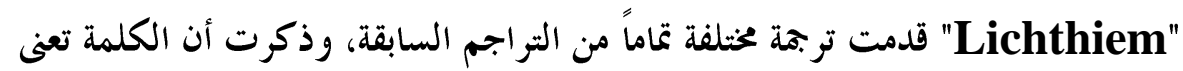
"maligned"

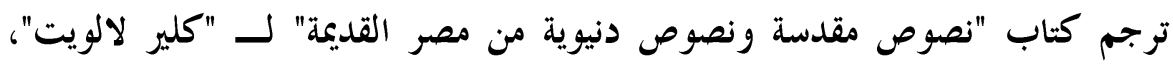

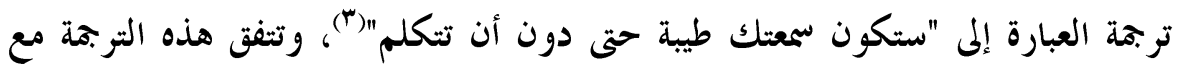

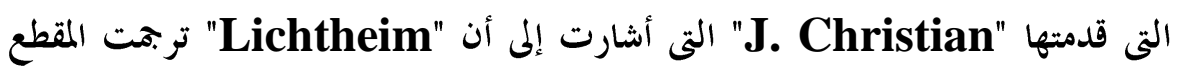

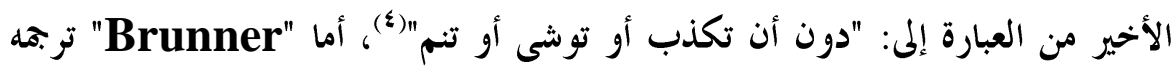

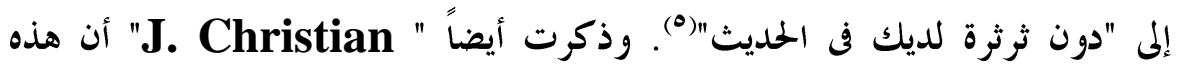

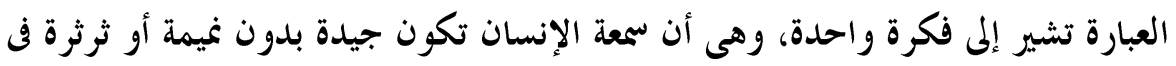

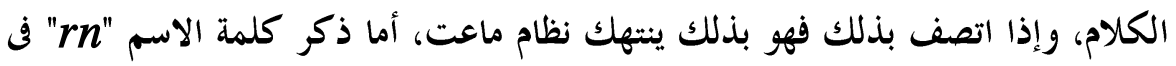

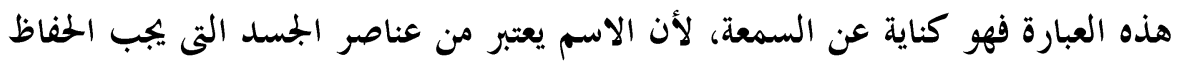

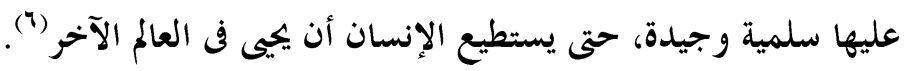

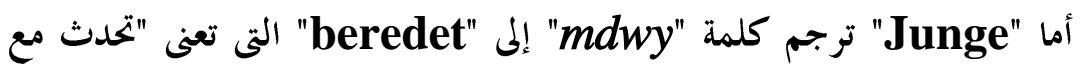

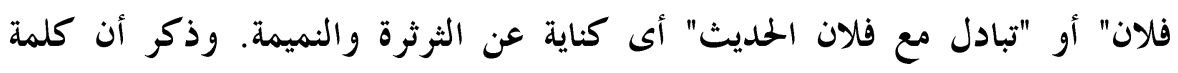

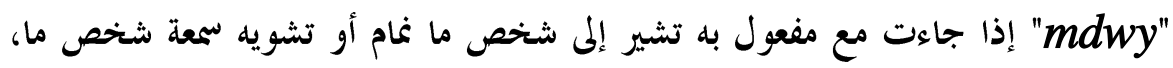

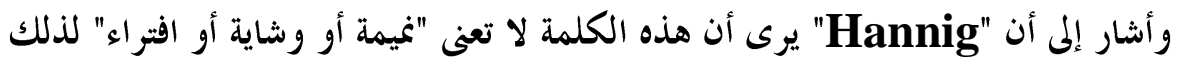

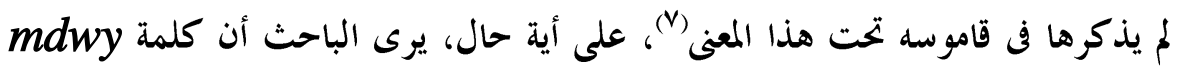

(1)S. Quircke, op. cit., p. 94.

(2)M. Lichtheim, op. cit., I, p. 67.

$$
\text { (ب) (ب) كلي لالويت: المرجع السابق، ص بساب. }
$$

(4)M. Lichtheim, op. cit., p. 67.

(5)H. Brunner, Die Weishitsbïcher der Ägypter, Zürich und München, 1991, 1991, 109- 132= Altägyptische Weisheit-Lehren Für das Leben-Eingeleitet, über setzt und erläutert, Die Bibliothek der Alten Welt, Reihe Der Alte Orient, Zürich und München, 1988.

(6) J. Christian, op. cit., p. 82.

(7)F. Junge, op. cit., p. 228. 
تشير في تعاليم بتاح حوتب إلى النميمة أو ثرثرة الكلام والقيل والقال، لأنه ليس من

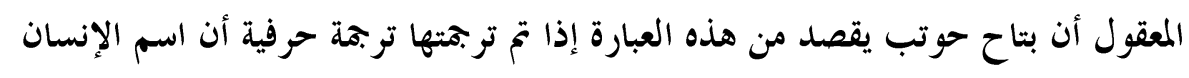

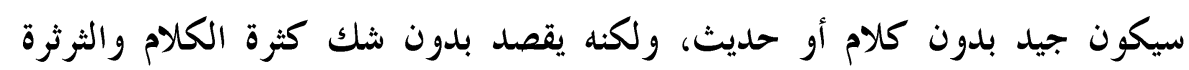

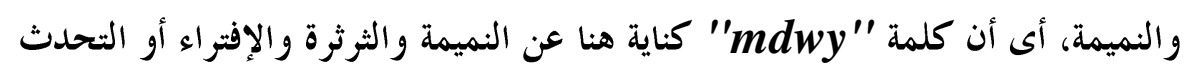

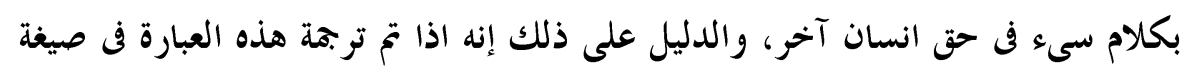

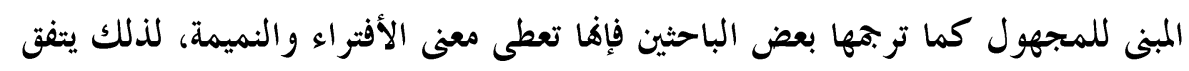

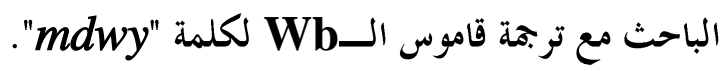

$$
\underline{h d i} \hat{\phi} \times{ }^{2}-\varepsilon
$$

فعل hdi

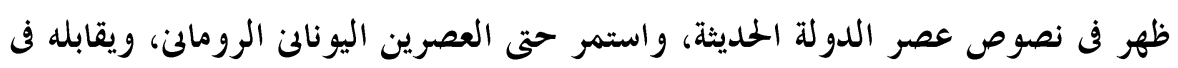

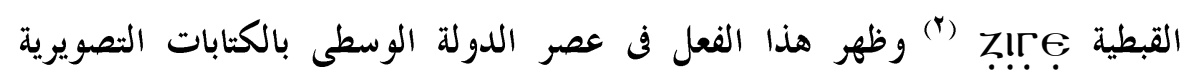
التالية:(")

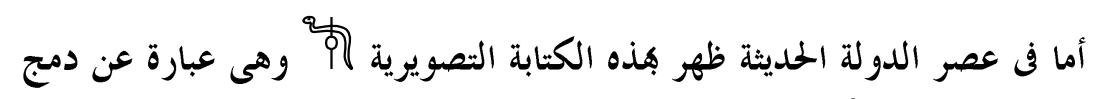

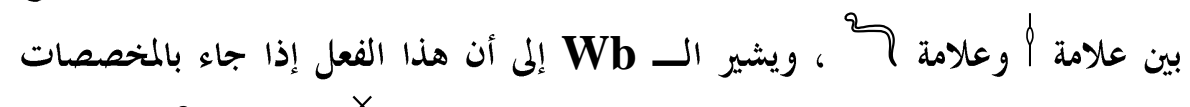

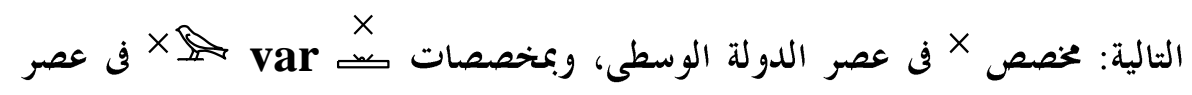

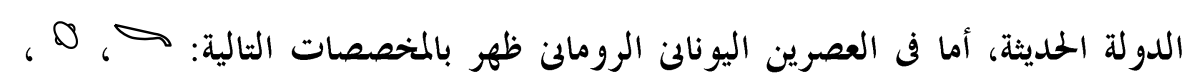

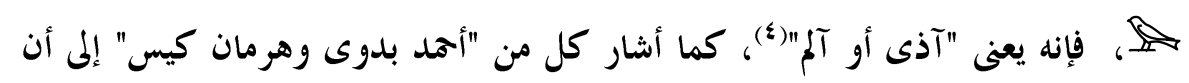
كلمة

(1)Wb III, 212; R. Hannig, Handwörterbuch, p. 1407; R. Faulkner, CD, p. 182.

(2)Wb III, 212.

(3) $W b$ III, 212.

(4)Wb III, 212; R. Faulkner, CD, p. 182.

$$
\begin{aligned}
& \text { (0) أمد بدوى وهرمان كيس: المرجع السابق، ص YVY. } \\
& \text { ro }
\end{aligned}
$$




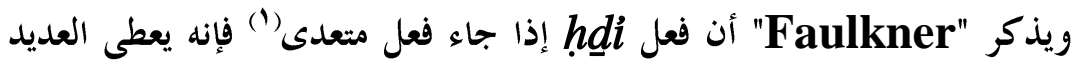

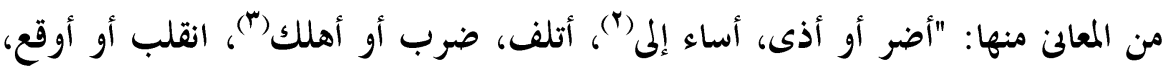

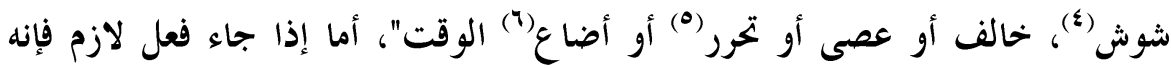

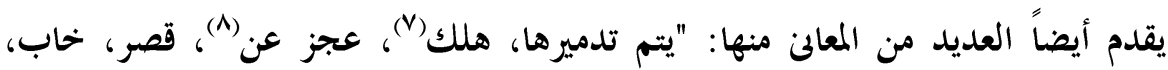

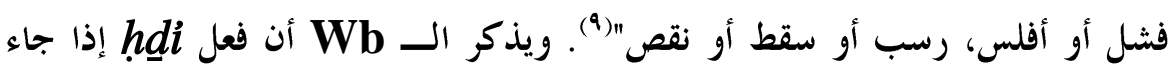

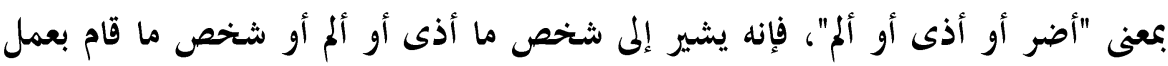

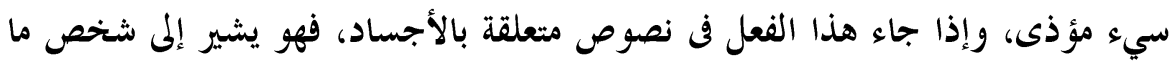

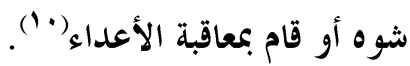

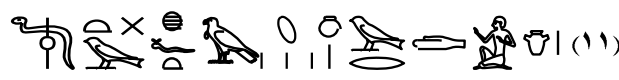

hdidit hfwt nw wrd-ib

معاقبة الأعداء بواسطة wrd-ib (الإله أوزير)

(1)R. Faulkner, CD, p. 182.

(2)A. H. Gardiner, Die Klagen des Bauern Literarische Texte des Mittleren Reiches I, Berlin, 1908, Bl 169;

F. Vogelsang, Kommentar zu den Klagess des Bauern, Untersuchingen, 6, Leipzig, 1913, reprint, Hild-esheim, 1964, Bl. 169.

(3) Urk IV, 1058, 2; Urk VII, 53, 11; A. H. Gardiner, The Admonitions of an Egyptian Sage from a hieratic in Leiden (Pap Leiden 344 recto), Leipzig, $1909,10,6$.

(4)P. Westcar 6, 4= A. Erman, Die Märchen des Papyrus Westcar, 2 Bde, Berlin, 1890.

(5)Urk IV 974, 3; 1776, 12.

(6)P. Prisse, 7, 9= E. Dévaud, op. cit., p. 26.

(7)A. H. Gardiner, op. cit., p. 10, 2.

(8)Ibid., 3, 8, 11; 5, 1.

(9)Urk IV, 351, 6; 994, 3.

(10)Wb III 212, 213, 1-2.

(11)Wb III, Belegstellen III, 213 (3), p. 68. 


$$
\begin{aligned}
& \text { حرفياً القلب المتعب (وصف لموت الإله أوزير)(1) } \\
& \text { كما ذكر فعل hdi }
\end{aligned}
$$

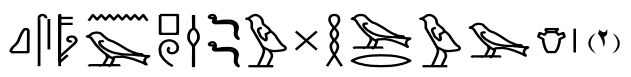$$
\text { ksn pw hִdi }(h \underline{d} \underline{d} \underline{d} w) h w r w i b(r)
$$

$$
\text { البائس هو (الذى) يؤذى أو يضرر الرجل الفقير(๕) }
$$

وقد أشار أيضاً كل من الــ Wb و Hannig إلى أن فعل hdi إذا جاء بمعنى

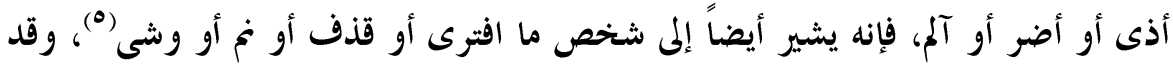

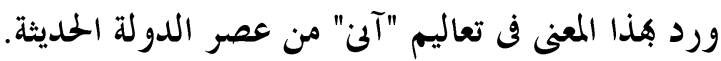

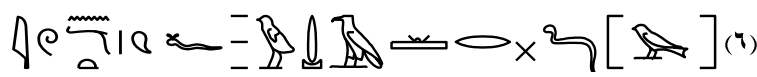

$$
\begin{aligned}
& \text { iw } n s . f w \underline{d} 3 \text { r hadi } \\
& \text { كلامه (حرفياً لسانه) خالى / مُعافى من النميمة (حرفياً الأذى) (v) }
\end{aligned}
$$

(1)R. Faulkner, CD, p. 65; E. A. W. Budge, The book of The Dead, vol. I, text, London, 1898, 19, 13; A. de Buck, Egyptian Reading Book, vol. III, Leyden, 1948, p. 15.

(2) P. Prisse, 6, 3= E. Dévaud, op. cit., p. 20; Z. Žaba, op. cit., p. 23.

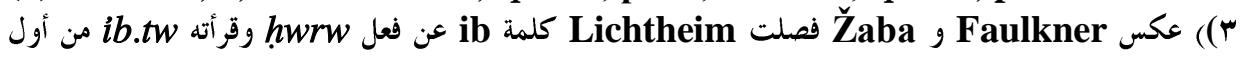

$$
\text { سطر رقم } 1 \text { في فردية Prisse. }
$$

M. Lichtheim, op. cit., p. 77, note (10); Z. Žaba, op. cit., p. 116, Note (75); R. O. Faulkner, $C D$, p. 166.

(4 )S. Quircke, op. cit., p. 91; Lichtheim, op. cit., p. 64; Z. Žaba, op. cit., p. 73.

(5)Wb III, 213, 3; R. Hannig, Handwörterbuch, p. 1407.

$$
\text { أشار الـ Wb إلى أن فعل }
$$

P. Anastasi I 28, 2= A. H. Gardiner, Egyptian Hieratic Texts, Leipzig, 1911.

(6)E. Suys, op. cit., p. 3 (1, 9).

(7) E.Suys, op.cit ,p.4 
ويترجم فعل كِ

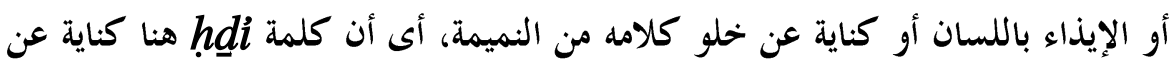

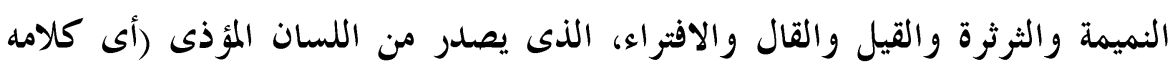

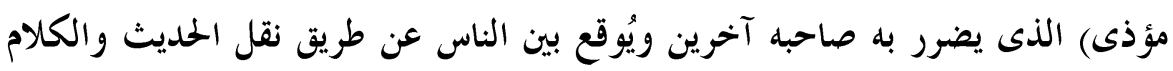
من قوم إلى قوم على جهة الإفساد والشر، والذى يقوم أيضاً لسانه (أى كلامه) بإطلاق

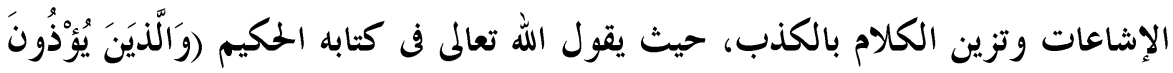

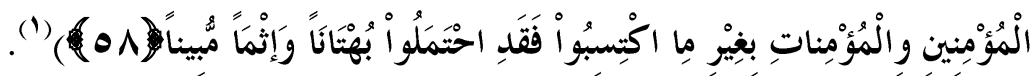

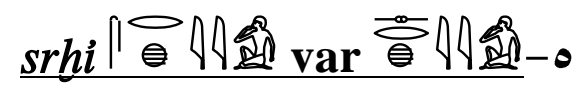

ذكر الـ Wb أن اسم srhi ظهر في النصوص الأدبية الخاصة بعصر الدولة

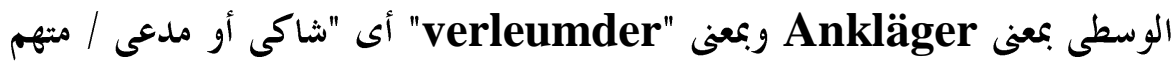

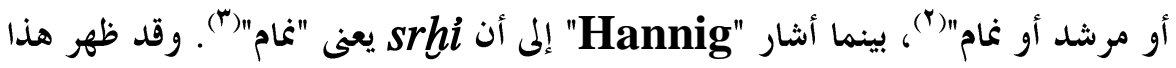

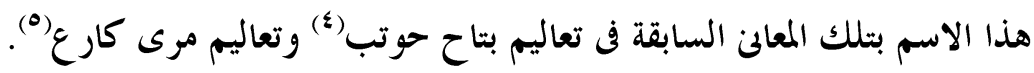

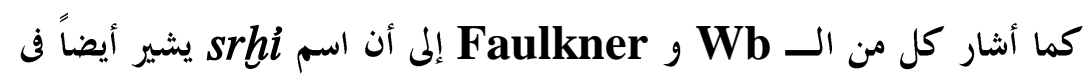

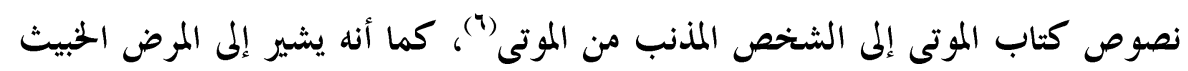

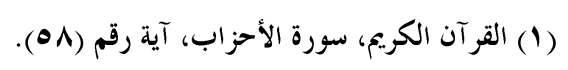

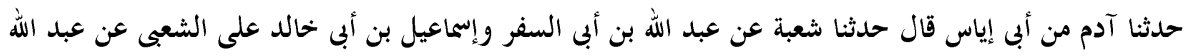

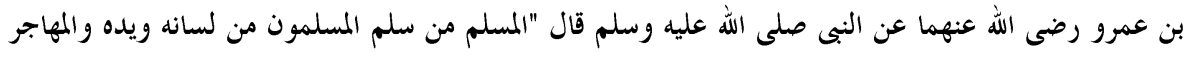
من هجر ما فيى الله عنه".

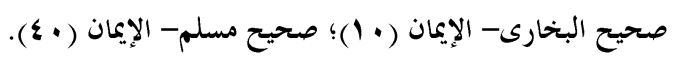

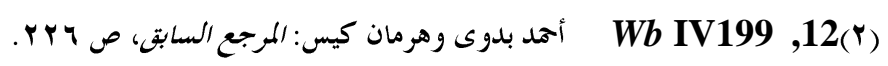

(3) R. Hannig, Handwörterbuch, p. 1407.

(4) P. Prisse, 15, 1,= E. Dévaud, op. cit., p. 43; (484- 485) (Max 34); Z. Žaba, op. cit., p. 54.

(5) J. F. Guach, Studien zur Lehre Für Merikare, Wiesbaden, 1992, p. 174, 54.

(6)R. O. Faulkner, $C D$, p. 236; Wb IV, 199, 13; Urk IV, 1004, 16. 
والروح الشريرة فى النصوص الطبية(')، أما إذا دون بمخصص الإله جحوتى له (ه) فإنه يشير إلى إله العلم والمعرفة جحوتى

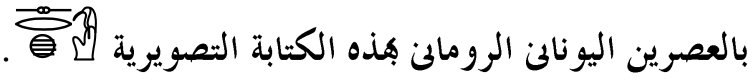

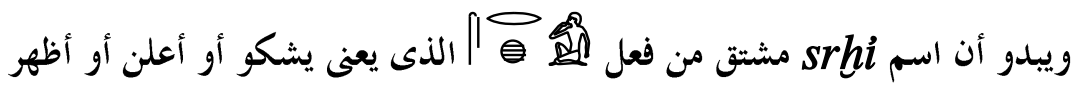

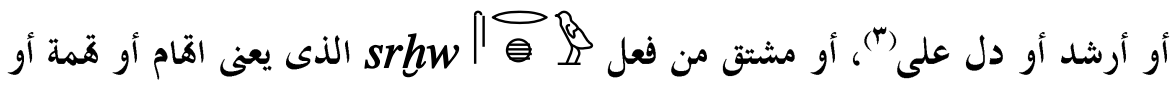

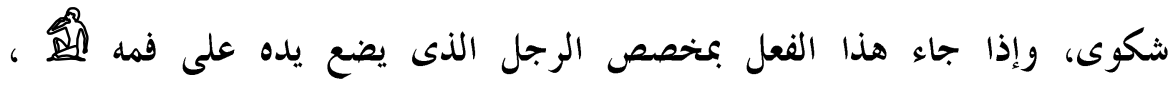

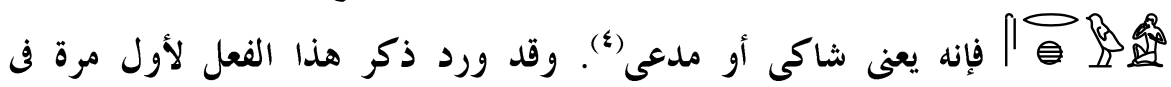

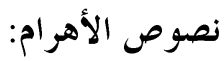

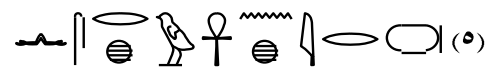

$$
\begin{aligned}
& n \text { srh } \text { `nh ir } \\
& \text { "ليس هناك حى يوجه اتحاماً لم...." }
\end{aligned}
$$

على أية حال، فقد ظهر اسم srhi بمعنى "شاكى/ أو مدعى أو متهم أو نغام" في تعاليم بتاح حوتب وتعاليم مرى كارع:

(1) Wb IV, 199, 14; R. O. Faulkner, $C D$, p. 236; P. Ebers 1, 5 W. Wreszinski, Die Medizin der alten Ägypter 3: Der Papyrus Ebers, Leipzig, 1913; J. H. Breasted, The Edwin Smith Surgical Papyrus, 3 Bde, Chikago, 1930.

(2)Wb IV, 199, 10; J. de Morgan, Kom Ombos (Catalogue des monuments et inscriptions de L'Egypte antique, vol. I, Wien 1894, I, 122, 159.

(3) Wb IV, 199; R. O. Faulkner, CD, p. 236; Urk, IV, 484, 9; 511, 8.

(4) $W b$ IV 199, 11; R. O. Faulkner, CD, p. 236.

(5) Pyr 386 a.

(6) R. O. Faulkner, Pyr, p. 78. 


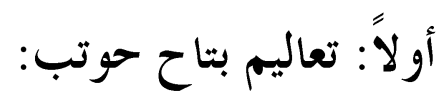

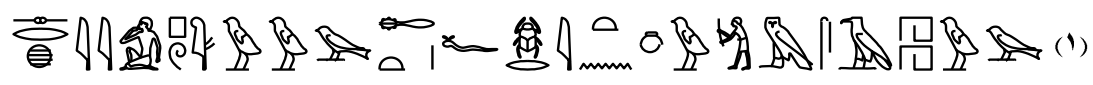

\section{srhi $p w \check{s} w(w) h t . f h p r i t n w ~ m ~ s 3 h h w$}

المدعى / الشاكى/ النمام هو (الذى) عقله (حرفياً بطنه أو جسده) خالى (")،

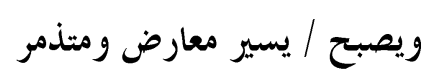

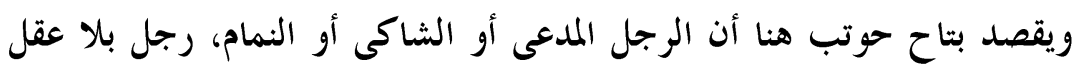

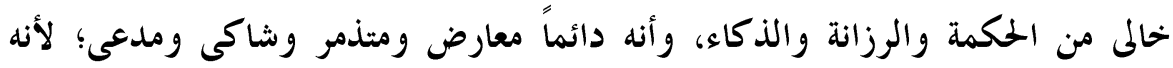

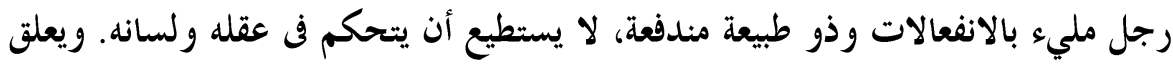
"Žaba"

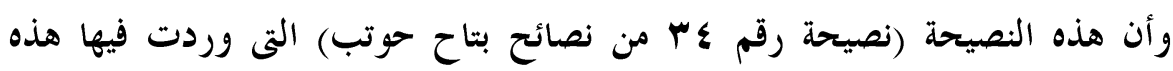

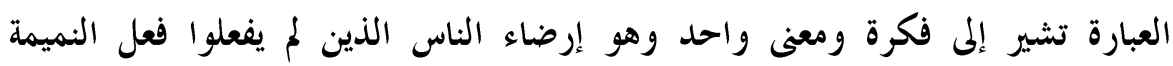

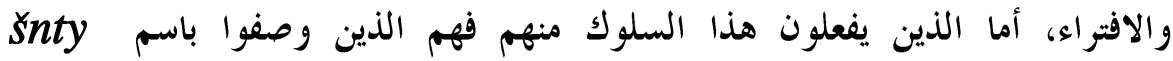

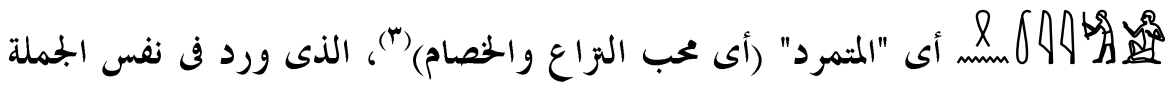

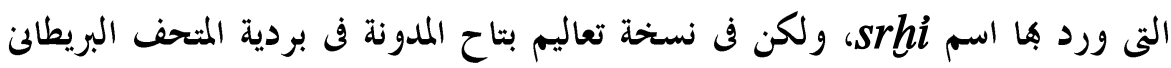

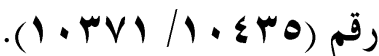

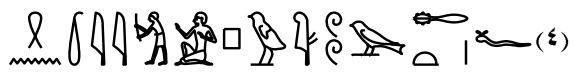

$$
\begin{aligned}
& \text { snty } p w \text { šw(w) ht.f }
\end{aligned}
$$$$
\text { المثمرد هو الذى عقله (حرفياً بطنه أو جسده) خالى)(1) }
$$

(1)P. Prisse 15, 11= E. Dévaud, op. cit., p. 43; (484- 485) (Max 34); Z. Žaba, op. cit., p. 54.

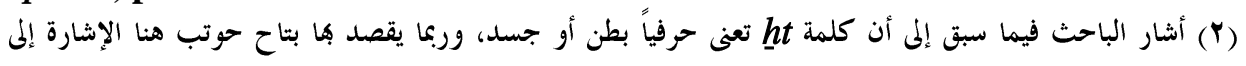

(3)Z. Žaba, op. cit., p. 158 (484).

(4)P. Brit Mus 10371/ 10435511 (Max. $\alpha+17$ )= E. Dévaud, op. cit., p. 43;

Z. Žaba, op. cit., p. 54. العقل وبالتحديد الفكر الكامن في العقل. 
وقد اتفقت تراجم الباحئن حول معنى اسم srhi الذى ورد في تعاليم بتاح

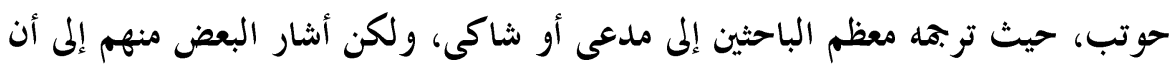

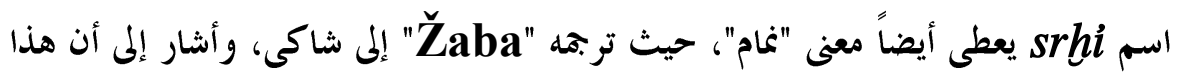

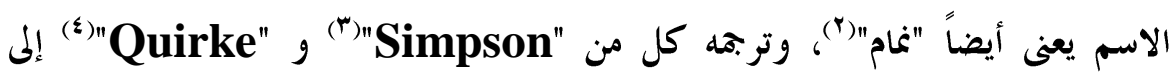

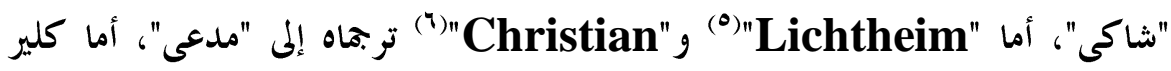

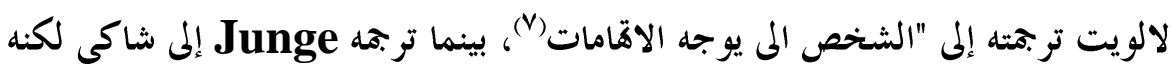

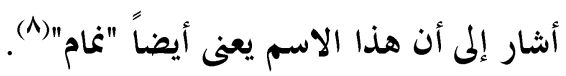

ويرى الباحث أن اسم srhi الذى ورد في تعاليم بتاح حوتب يشير إلى الشخص

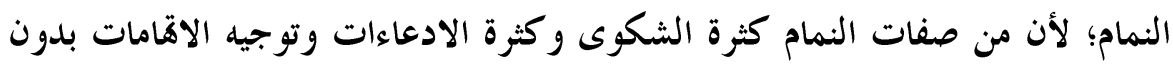

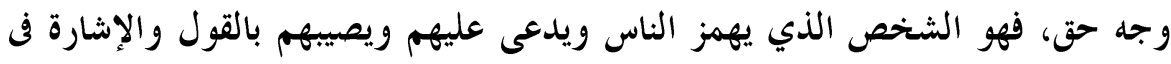
حضورهم وفى غيبتهم على حد سواء، لذلك يمكن القول أن اسم

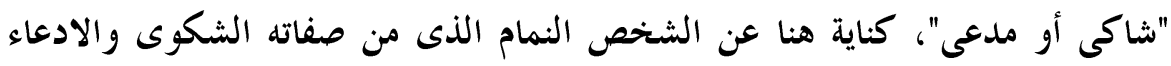

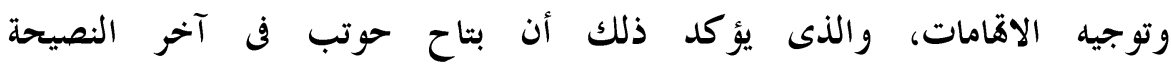

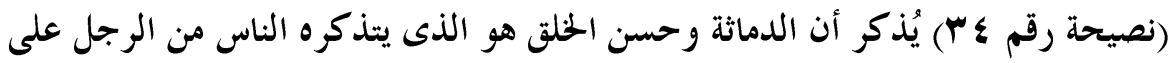

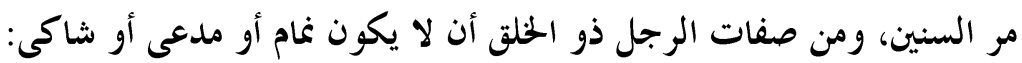

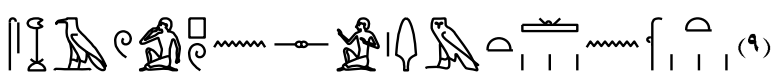

\section{sh3 pw n s i3mt n rniwt}

(1)Ibid., p. 98.

(2) Ibid.,p. 98, p. 158.

(3)W. K. Simpson, op. cit., p. 171.

(4)S. Quirke, op. cit., p. 98.

(5)M. Lichtheim, op. cit., I, p. 72.

(6)J. Christian, op. cit., p. 140.

$$
\text { (V) كليز لالويت: المرجع السابق، ص ای؟. }
$$

(8) E. Junge, op. cit., p. 182, p. 201, p. 255.

(9)P. Prisse, 15, 2= E. Dévaud, op. cit., p. 44; Z. Žaba, op.cit., p. 54. 
"حسن الأخلاق/الدماثة هى ما يتذكره (الناس) من المرء على مر السنين"(1)

ثانيا: تعاليم مرى كار ع:

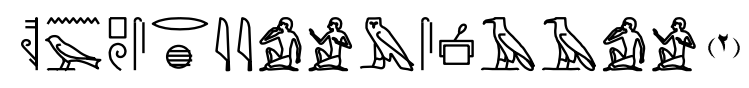

ksn pw srhi m s33

$$
\text { "بائس هو المدعى عليه من رجل حكيم" أو }
$$

ويلاحظ هنا أن اسم srhi ترجم هنا إلى متهم أو "مدعى عليه"، وقد اتفقت

معظم تراجم الباحثين لاسم srhi الذى ورد في تعاليم "مرى كارع" حول هذا المعنى، حيث ترجم Gardiner العبارة التى ورد فيها اسم Srhi إلى "ويل له الذى يتهمه

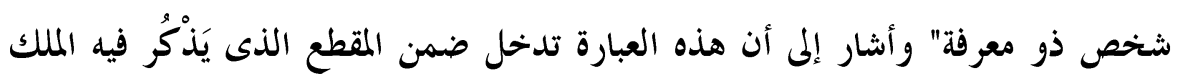
خيتى الثالث ابنه مرى كارع بيوم الخاكمة في العالم الآخر (\&). أما Simpson ترجم اسم اسم srhi إلى "accused" إلى متهم/ مدعى عليه" وعلق على العبارة التى ورد فيها هذا الاسم بقوله "لأنه هو الذى يستخدم معرفته لقهر الفقراء"(•). وقد ترجما كل من

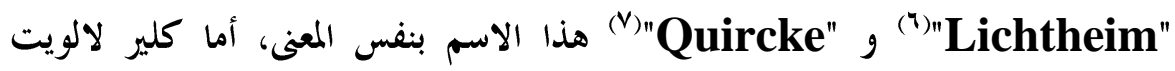
ترجت اسم srhi إلى مُثل الاعَام وأشارت أن الحكيم أو الرجل ذو المعرفة هنا هو الإله

(1) Z. Žaba, op. cit., p. 98; W. K. Simpson, op. cit., p. 171; S. Quirke, op. cit., cit., p. 98; M. Lichtheim, op. cit., p. 72.

(2)J. F. Quack, op. cit., p. 174 (54).

(3)Ibid., p. 25, A. H. Gardiner, "New Literary Works from Ancient Egypt", in: JEA, vol. I, 1914, p. 27; W. K. Simpson, op. cit., pp. 183- 184;

M. Lichtheim, op. cit., p. 101.

(4) A. H. Gardiner, op. cit., p. 27.

(5) W. K. Simpson, op. cit., p. 184, Note (1).

(6) M. Lichtheim, op. cit., p. 101.

(7) S. Quirke, op. cit., p. 115. 
"جحوتى" ('). أما "Quack" ترجمه إلى "Ankläger" أى "مدعى عليه أو متهم" (؟). ويتضح للباحث مما سبق تقديمه من تراجم للباحثين لاسم Srhi أن هذا الاسم لا

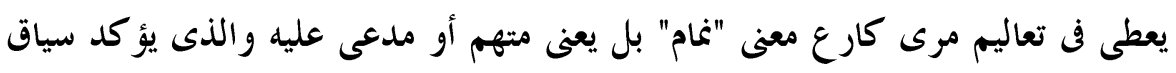

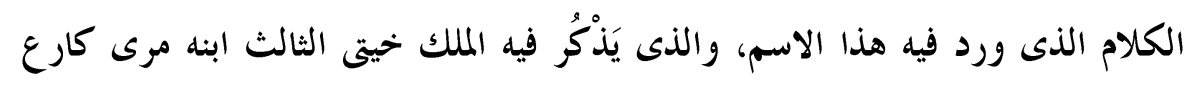

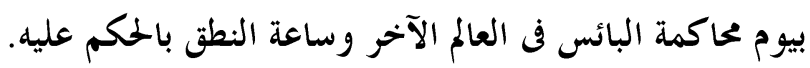

$$
\underline{s d w} \| \underline{\Delta}-1
$$

فعل Sd سواء كانت صحيحة أم معتلة أم مشددة(")، وفعل

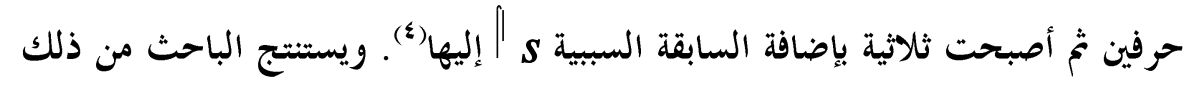

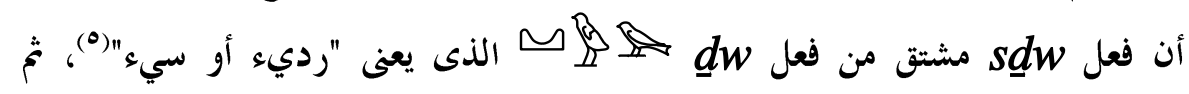
أدخلت عليه السابقة السببية $s$ ال، وأصبح الفعل في النصوص الأدبية التى ترجع لعصر الدولة الوسطى واستمر ظهوره حتى العصر المتأخر،

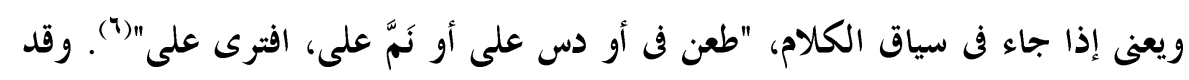

(2) J. F. Quack, op. cit., p. 35.

(3) A. H. Gardiner, Egyptian Grammar $3^{\text {rd }}$-ed, § 275, p. 211-212;

K. Sethe, Das agyptische Verbum im altägyptischen, new ägyptischen, und Koptischen, vol. I, Leipzig, 1902, §§ 350- 356;

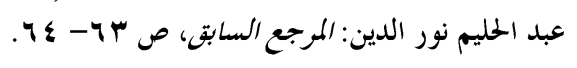

(4) Wb VI, 380; R. Hannig, Handwörterbuch, p. 1407; R. O. Faulkner, CD, p. 258.

(5) $W b \mathrm{~V}, \mathbf{5 4 5}$;

$$
\text { أمد بدوى وهرمان كيس: المرجع السابق، ص به r. }
$$

(6) Wb VI, 380, 7-8; R. O. Faulkner, Handwörterbuch, p. 1407;

$$
\text { أهمد بدوى وهرمان كيس: المرجع السابق، ص • ؟ ؟r. }
$$


ظهر هذا الفعل فى عصر الدولة الوسطى بالكتابات التصويرية التالية: (1) هم هم هـ , |

أما فى عصر الدولة الحديثة دون بالكتابات التصويرية التالية:

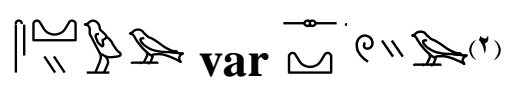

وقد أشار "Faulkner" إلى أن كلمة

"Slander"

Hannig

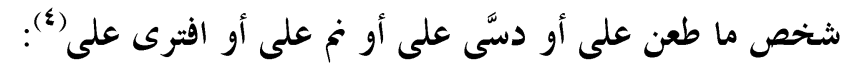

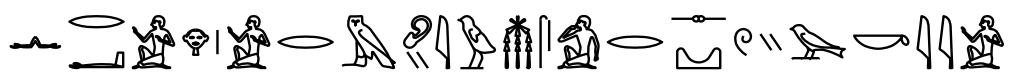
$\Longleftarrow l_{a \sim} w \omega^{(0)}$

n rdi.i hr.i s $\underline{d}$ my iw ms r sdwy ky m inwt.f

"لا تجعل وجهى ضد (الذى) أصغى إلى النم على الآخر فى حضرته"

أما إذا جاء فعل

$\sim \sim$ 几

(1) $W b$ VI, 380.

(2) $W b$ VI, 380.

(3) R. O. Faulkner, CD, p. 258.

(4) Wb VI, 380, 7.

(5) Urk IV, 1828, 2; G. Legrain, "Rapport sur les travaux executes á Karnak du 25 Septembre au 31 actobre, 1901", in: ASAE, 1901, p. 283; CG 42127,7= G. Legrain, Statues et Stauet tes des rois ét des paticuliers, vol. 2, Kairo, 1906.

(6) $W b$ VI, 380, 8.

(7) Urk IV, 1533, 15; B. Coming, Egyptian Historical Records of the Later eighteenth dynasty, Fascide 2, London, 1984, p. 202; K. Piehl, Inscriptions 
$n$ sdwi $n$ is $h r$ sp $n$ s'r.i $\underline{d} w t r$ Th

"أنا لا أنم على (أى شخص) ولا يتعلق جى حتى ذنب، ولا أُدخل أى شر إلى القصر"

أما إذا جاء فعل

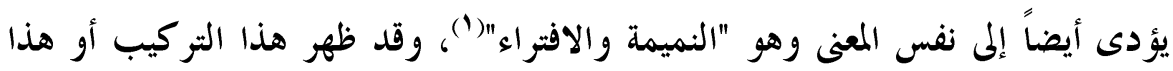

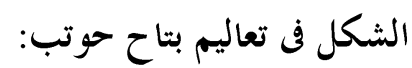

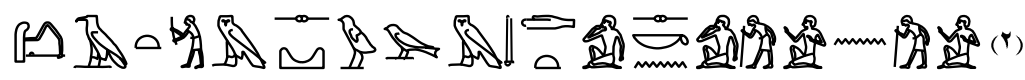

‘ $h 3 t(w) m s \underline{d} w$ m mdt skn.ti wr $n$ wr "احذر من النميمة في الكلام/ الحديث التى توقع (بين) عظيم وعظيم"

وهذه العبارة جاءت ضمن النصيحة التى ينصح فيها بتاح حوتب الأجيال بقوله

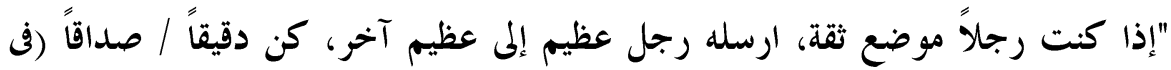

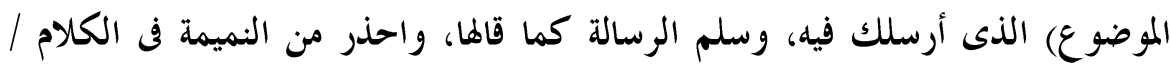

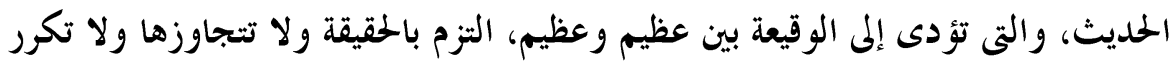

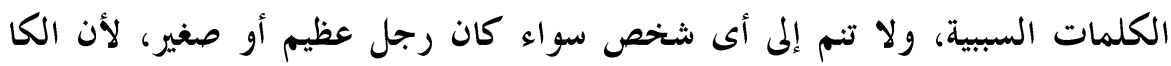

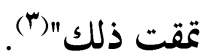

ويلاحظ الباحث أن هناك صلة بين هذه النصيحة (نصيحة رقم ^) وبين النصيحة

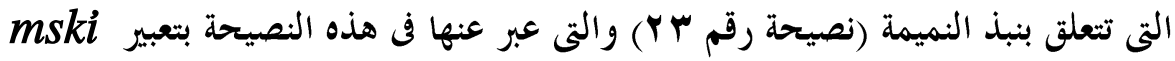

hiéroglyphiques recueillies en Europe eten Egypte, vol. I, Leipzig, 1886, pl. xvi; T. Säve Söderberg; Einige ägyptische Denkmäler in Schwedan, Leipzig, 1946, p. 5 ff; A. Hermann, Die Stelan der Theban Ischen der 18 Dynastie, $\ddot{A F}, 11,1950$, p. 55, 12.

(1) Wb VI, 380, 8; R. Hannig, Handwörterbuch, p. 1407.

(2) P. Prisse, 7, 4= E. Dévaud, op. cit., p. 24, (149- 150) (Max 8); Z. Žaba, op. cit.,

(3) Z. Žaba, op. cit., p. 77; A. Erman, op. cit., p. 58; W. K. Simpson, op. cit., p. 163; M. Lichtheim, op. cit., I, p. 65; S. Quircke, op. cit., p. 92. 
n mdt

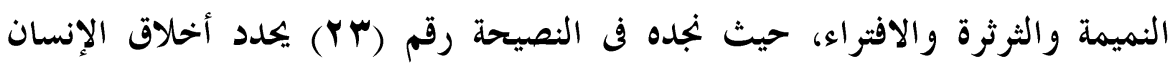

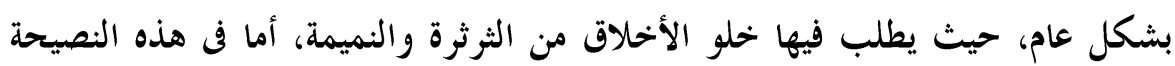

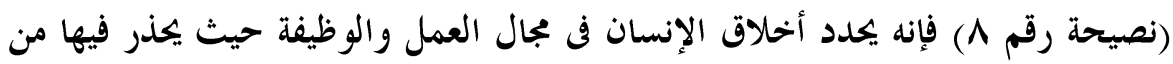

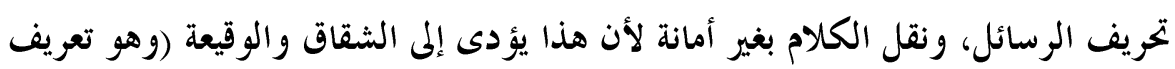
النميمة) والحث على الالتزام بالأمانة والصدق في تبليغ الرسائل ونقل الكلمات الكان.

وقد اختلفت تراجم الباحثين لفعل

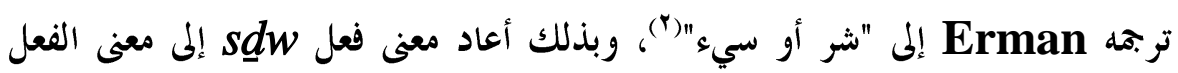
الذى اشتق منه وهو ww Erman Quirke و أما تربمة "Simpson" اختلفت عن تراجم الباحثين السابقين، حيث تربمه إلى

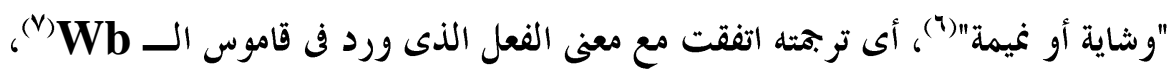

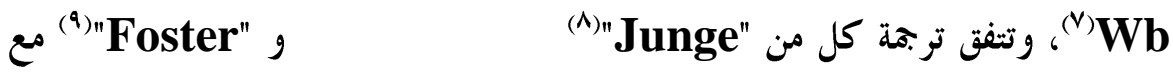
تربمته.

وأشار "Junge " إلى أن الصيغة الفعلية التى ورد فيها الفعل wdِs، صيغة فعلية

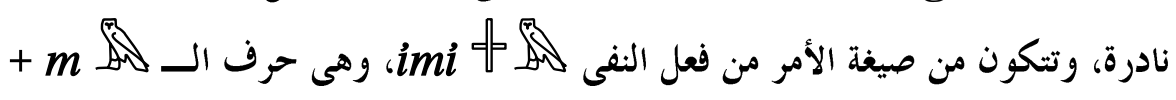

(1) Wb II, 150, 7; R. Hannig, Handwörterbuch, p. 514, 714; P. Prisse, 11, 5

E. Dévaud, op. cit., p. 36 (Max 23); Z. Žaba, op. cit., p. 44.

(2) A. Erman, op. cit., p. 58.

(3) Z. Žaba, op. cit., p. 77.

(4) M. Lichtheim, op. cit., I, p. 65.

(5) S. Quircke, op. cit., p. 92.

(6) W. K. Simpson, op. cit., p. 163.

(7) $W b$ VI, 380, 8.

(8) F. Junge, op. cit., p. 175, p. 192.

(9) J, Foster, op. cit., p. 37. 
معمول/ مفعول النفى (Christian" تر متحت الفعل إلى "قوة أو

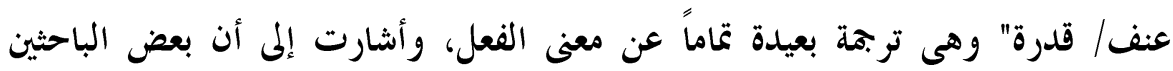
يعتقدون أن هذه العبارة تشير إلى تجنب النميمة والقذف (ب).

ويرى الباحث أن فعل

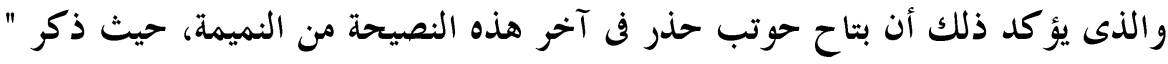

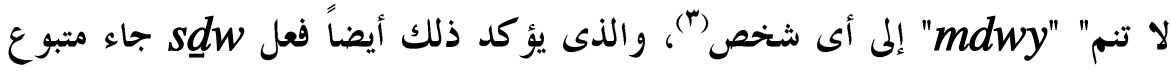

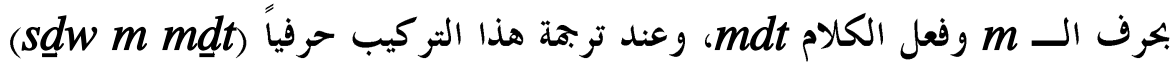
فهو يعطى أيضاً معنى النميمة والافتراء، لأن التركيب يعنى حرفياً "الشر أو الأذى أو أو الواليا

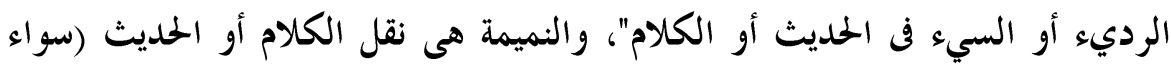

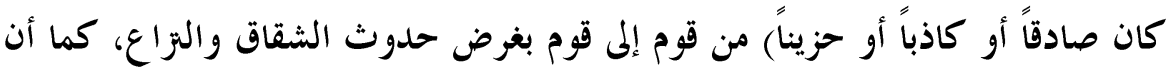
الحديث أو الكلام السيء هو بالتأكيد النميمة. $s t m$ 泟通 $-V$

ذكر الـ Wt أن في ظهر في نصوص عصر الدولة الوسطى، وأنه إذا

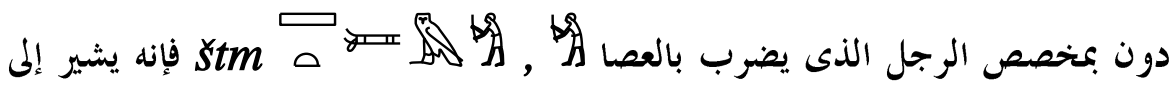

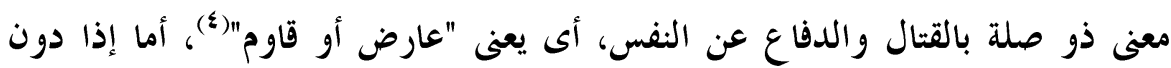

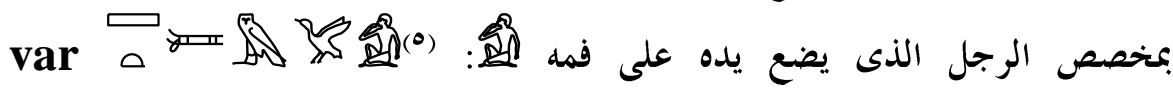
泟余

(1) F. Junge, op. cit., p. 218; A. H. Gardiner, Egyptian Grammar $3^{\text {rd }}{ }_{-}^{e d} \S \S$ 340- 341; pp. 260- 261.

(2)Christian, J., op. cit., p. 62, Note (78).

(3) P. Prisse, 7, 4= E. Dévaud, op. cit., p. 24, (159), (Max 8); Z. Žaba, op. cit., p. 28, p. 77; p. 124 (159).

(4) Wb VI, 557, 12; K. Sethe, Aegyptische Les estïcke, Leipzig, 1928, p. 7, 21;

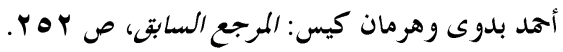

(5) Wb VI, 557, 13-14; P. Prisse, 11, 13= E. Dévaud, op. cit., p. 37, (373) (Max 25); Z. Žaba, op. cit., p. 46. 
فإنه يشير إلى العنف والقوة والإهانة في الحديث، أى يعنى "شتم أو سب أو العبا

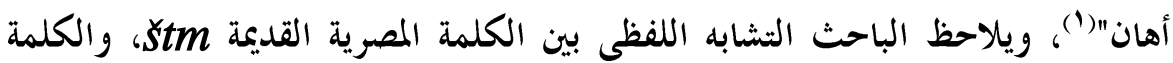
العر بية "شتم" فضلاً عن التشابه فى المعنى، وقد ظهر لهذا المعنى فـ تعاليم بتاح حوتب:

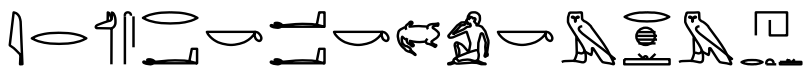

$$
\begin{aligned}
& \text { 马) } \$ \text { 为 }
\end{aligned}
$$

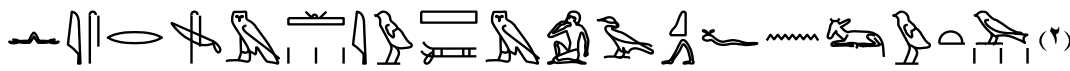

ir. wsr.k dd.k snd.k $m$ rh $m$ hrt d d $m$ wd $t p$ is $r$ sšm iw stm ' $k . f n$ iwt

"إذا كنت رجلاً قديراً فاعمل على أن يخشاك (الناس)، بسبب علمـ(سك)

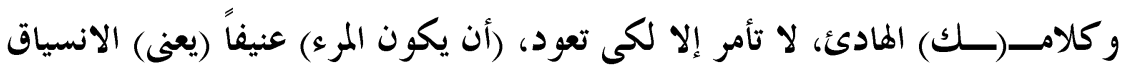

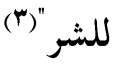

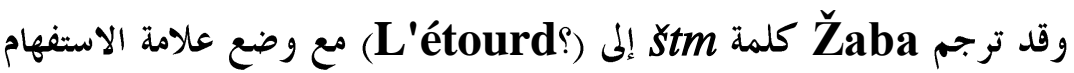

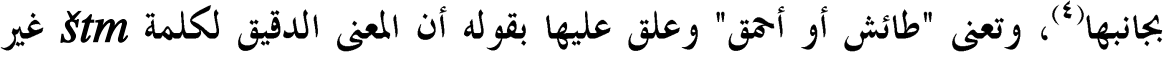

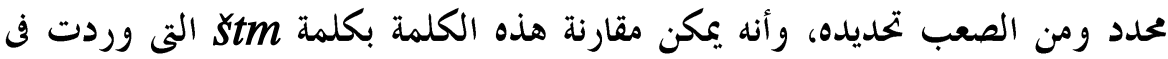

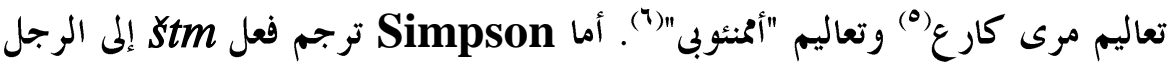

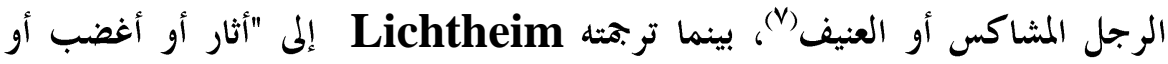

(1) Wb VI, 557, 13;

أهد بدوى وهرمان كيس: المرجع السابق، ص ror).

(2)P. Prisse 11, 13= E. De'vaud, op. cit., p. 37 (370- 371).

(3)M. Lichtheim, op. cit., p. 70; K. M. Simpson, op. cit., p. 168.

(4)Z. Žaba, op. cit., p. 91.

(5)J. F. Quack, op. cit., (147), p. 200.

(6) P. BM no. 10474= Lange, Das Weidhritbuch des Amenemope, Köbenhaven 1925, 21, 10; Z. Žaba, op.cit, p. 51.

(7)K. M. Simpson, op. cit., p. 168. 
استفز "(') وأشارت إلى هذا المعنى دُعِمَ من قبل Posener(") الذى قام بنشر جزء من

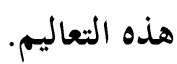

واتفقت ترجمة "Christian")" (") مع تربمة "Lichtheim"، لكنها أشارت

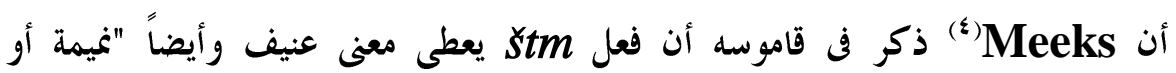

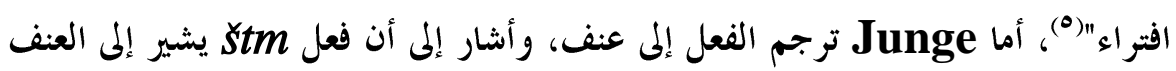

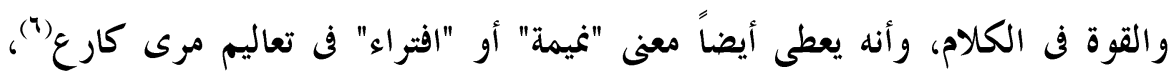

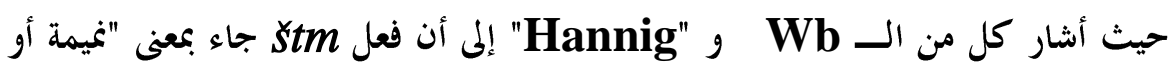

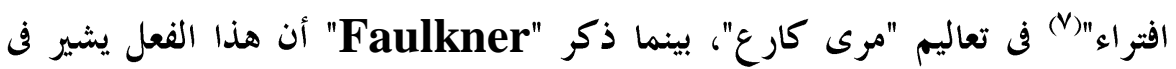

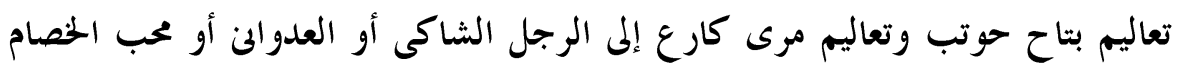

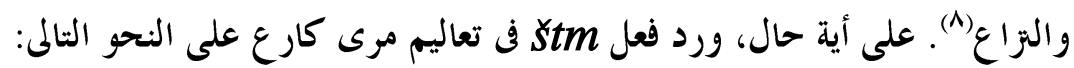

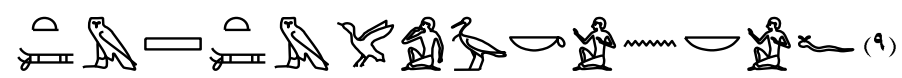

tm stm $b 3 k n n b . f$

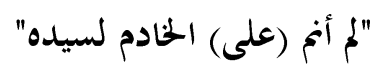

وترجم Quirke هذه العبارة إلى "م أشنكى/ أفضح/ أقم الحخادم لسيده"(').

(1)M. Lichtheim, op. cit., p. 70, p. 79, Not (43).

(2)G. Posener, "Section Finale d'une Sagesse Inconnue (Recherches

Littéraires II)", in: $R d E$ 7, 1950, pp. 71- 83.

(3) J. Christian, op. cit., p. 116.

(4)D. Meeks, Alex, I, p. 381.

(5) J. Christian, op .cit., p. 116, Note (238).

(6)F. Junge, op. cit., p. 179, p. 179, p. 198, p. 242.

(7)Wb VI, 557, 14; R. Hannig, Handwörterbuch, p. 1407.

$(8)$ R. O. Faulkner, CD, p. 273.

(9)J. F. Quack, op. cit., (147), p. 200.

(10) S. Quircke, op. cit., p. 119. 
على أية حال، يرى الباحث أن فعل Stm الذى ورد في تعاليم بتاح حوتب يشير إلى معنى العنف والقوة بالإهانة فى الكلام أى سب أو أهان أو شتم، ولا يشير إلى معنى

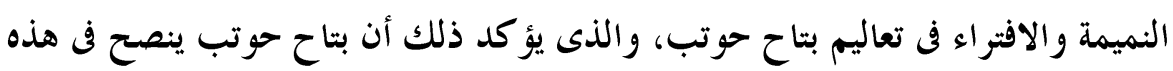

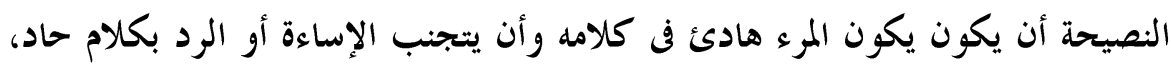

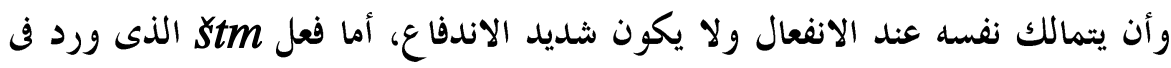

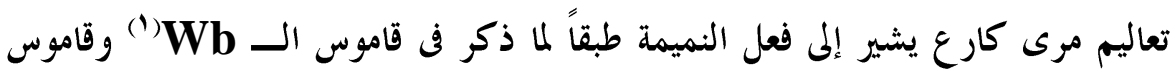

(")Hannig

(1)Wb VI, 557, 14.

(2)R. Hannig, op. cit., p. 1407. 


\section{نتائج البحث}

يتضح من خحلال الدراسة السابقة للمفردات والتعبيزات الدالة على النميمة في

نصوص التعاليم المصرية القديمة ما يلى:

أولاً: تنوع وتعدد المفردات والتعبيرات الدالة على النميمة فى نصوص التعاليم

المصرية القديمة، ويرجع ذلك إلى أن معظم نصوص التعاليم دونت بلغة العصر الوسيط التى تتميز بالازدهار والمفردات والتعبيرات والنضج الكامل، فهى المرحلة الكلاسيكية للغة المصرية القديمة التى دون بما معظم نصوص التعاليم.

ثانياً: يلاحظ في نصوص تلك التعاليم وجود مفردات وتعبيرات مباشرة تدل على

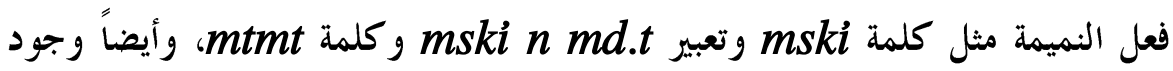
مفردات غير مباشرة تستخدم ككناية عن فعل النميمة مثل: , mdwy , hdi , srhi $s \underline{d} w, \breve{s t m}$

ثالثاً: يلاحظ أن المفردات والتعبيرات المباشرة الدالة على فعل النميمة مشتقة من أفعال تشير إلى النقاش والحوار، مثل اسم mtmt

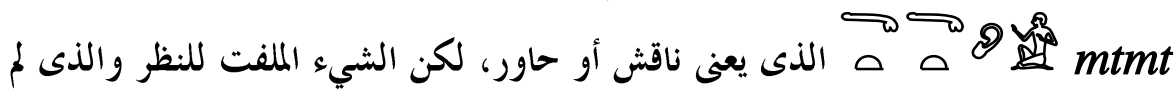

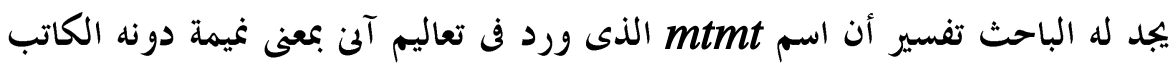

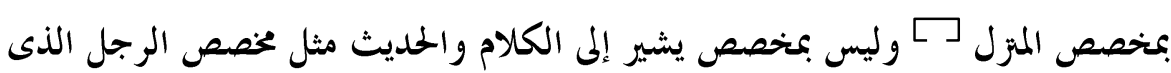
يمد يده إلى فمه

أما اسم mski

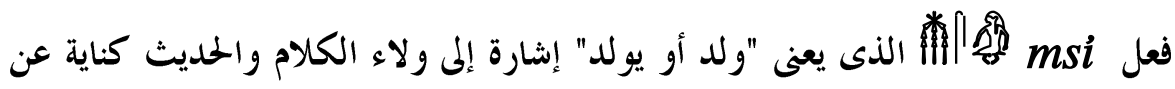
النميمة والثرثرة، ومن الختمل أن حرف الــ هـ دمج مع جذع فعل msi، ثم أضيف

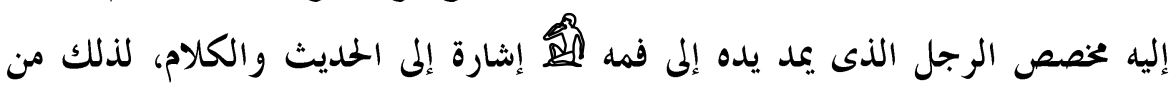
الختمل أن تعبير mski m md.t كان في الأصل msi n.k md.t أى في صيغة إلى

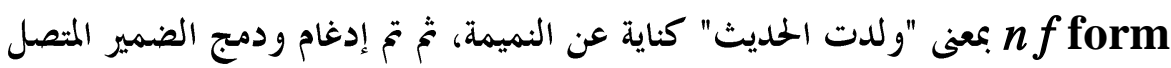




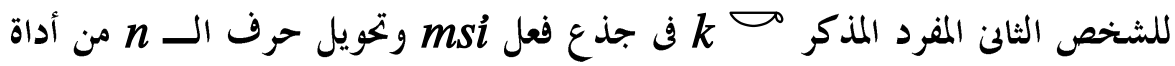

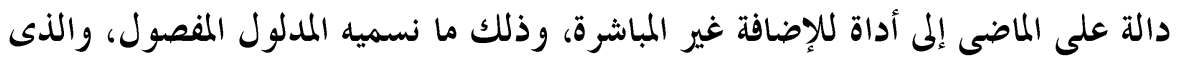

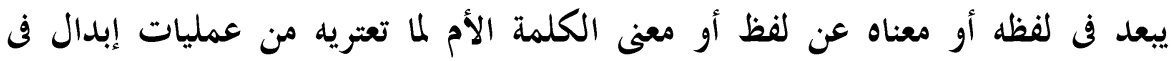
الأحرف أو قلب مكالن أو زيادة فى السو ابق واللواصق واختلاق المعن المعنى كلياً.

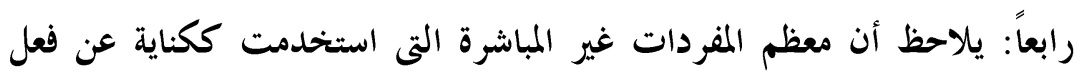

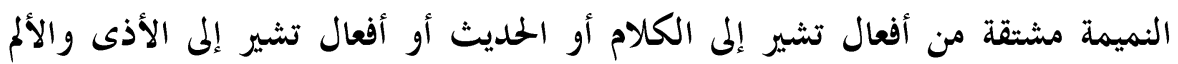

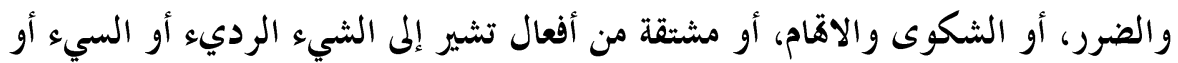
الشر أو العنف والقوة والسب والإهانة.

ו- فعل mdwy مشتق من فعل mdw الذى يعنى حكى أو تكلم عن. r - فعل hd

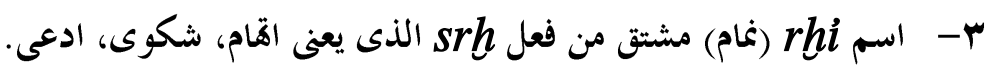
צ- فعل في

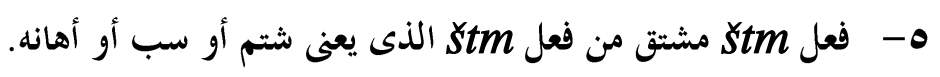

خامساً: أن فعل mdwy الذى ورد في تعاليم بتاح حوتب، يشير إلى النميمة والثرثزة؛ لأنه ليس من المعقول أن بتاح حوتب يقصد من الجملة التى التى ورد فيها هذا الفعل

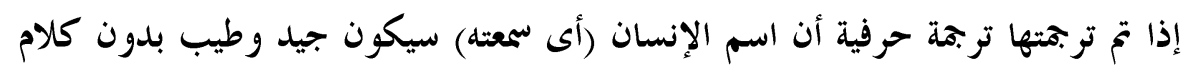

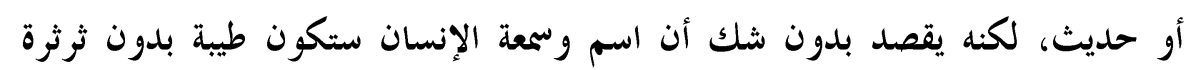

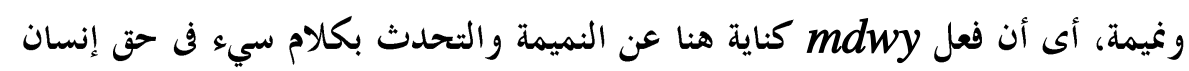

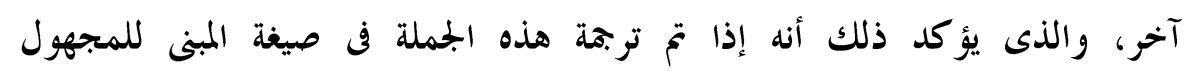
فإنها أيضاً تعطى معنى النميمة. (passive)

سادساً: أن فعل hd

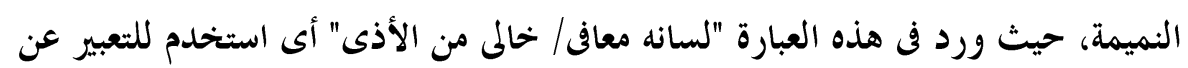

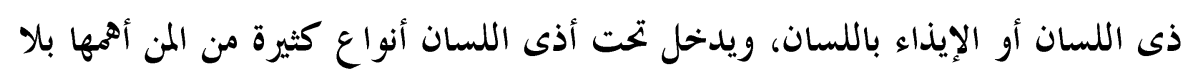
شك النميمة، أى أن فعل hd hil استخدم هنا ككناية عن النميمة. 
سابعاً: يتضح للباحث أن اسم srhi لا يعطى معنى "نام" في تعاليم مرى كارع،

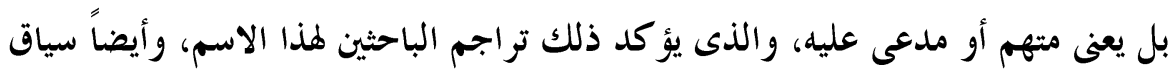

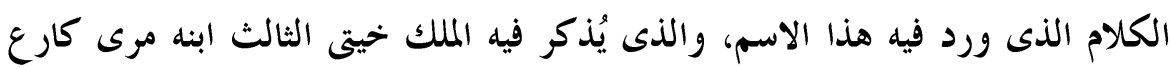

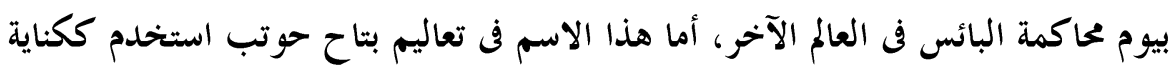

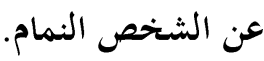

ثامناً: أن فعل

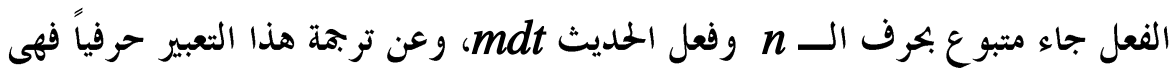

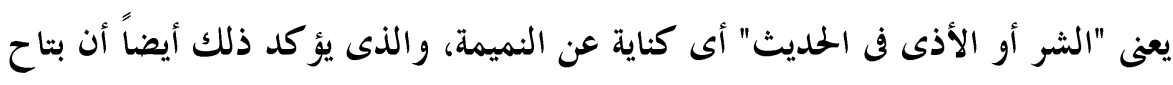

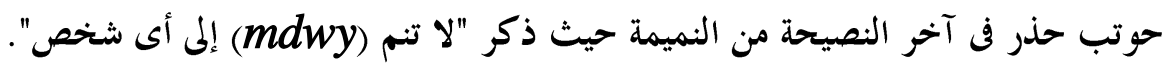

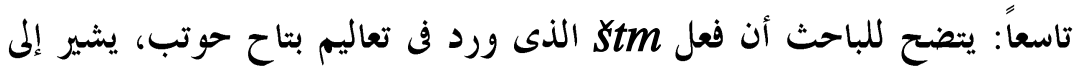

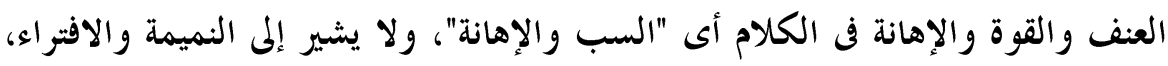

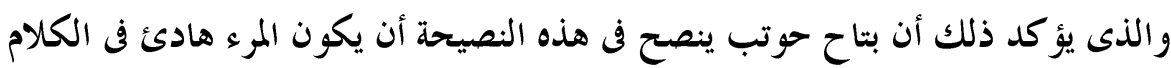

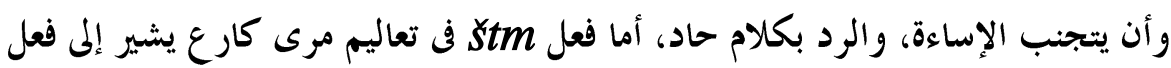

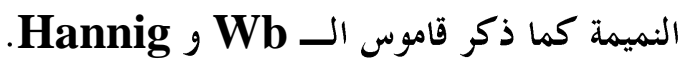

